\title{
American Medical Society for Sports Medicine position statement: concussion in sport
}

\author{
Kimberly G Harmon, ${ }^{1}$ Jonathan A Drezner, ${ }^{1}$ Matthew Gammons, ${ }^{2}$ Kevin \\ M Guskiewicz, ${ }^{3}$ Mark Halstead, ${ }^{4}$ Stanley A Herring, ${ }^{1}$ Jeffrey S Kutcher, ${ }^{5}$ \\ Andrea Pana, ${ }^{6}$ Margot Putukian, ${ }^{7}$ William 0 Roberts ${ }^{8}$
}

Endorsed by the National Trainers' Athletic Association and the American College of Sports Medicine

${ }^{1}$ Department of Family

Medicine, for Stanley Herring Department of Physical

Medicine and Rehabilitation, University of Washington,

Seattle, Washington, USA

2Vermont Orthopaedic Clinic,

Rutland, Vermont, USA

${ }^{3}$ Sports Medicine Research

Laboratory, University of North

Carolina at Chapel Hill, Chapel

Hill, North Carolina, USA

${ }^{4}$ Department of Pediatrics,

Washington University,

St. Louis, Missouri, USA

${ }^{5}$ Department of Neurosport,

University of Michigan, Ann

Arbor, Michigan, USA

${ }^{6}$ University of Texas, Austin,

Texas, USA

${ }^{7}$ Department of Athletic

Medicine, Princeton University,

Princeton, New Jersey, USA

${ }^{8}$ Department of Family

Medicine and Community

Health, University of

Minnesota, St Paul,

Minneapolis, USA

\section{Correspondence to}

Dr Kimberly G Harmon,

University of Washington,

Box 354410, Seattle,

Washington, USA;

kharmon@u.washington.edu

Received 30 October 2012

Revised 30 October 2012

Accepted 30 October 2012
To cite: Harmon $\mathrm{KG}$, Drezner JA, Gammons M, et al. Br J Sports Med 2013, 47, 15-26
ABSTRACT

\section{Purpose of the statement}

- To provide an evidence-based, best practises summary

to assist physicians with the evaluation and

management of sports concussion.

- To establish the level of evidence, knowledge gaps and areas requiring additional research.

Importance of an AMSSM statement

- Sports medicine physicians are frequently involved in the care of patients with sports concussion.

- Sports medicine physicians are specifically trained to provide care along the continuum of sports concussion from the acute injury to return-to-play (RTP) decisions.

- The care of athletes with sports concussion is ideally performed by healthcare professionals with specific training and experience in the assessment and management of concussion. Competence should be determined by training and experience, not dictated by specialty.

- While this statement is directed towards sports medicine physicians, it may also assist other physicians and healthcare professionals in the care of patients with sports concussion.

\section{Definition}

- Concussion is defined as a traumatically induced transient disturbance of brain function and involves a complex pathophysiological process. Concussion is a subset of mild traumatic brain injury (MTBI) which is generally self-limited and at the less-severe end of the brain injury spectrum.

\section{Pathophysiology}

- Animal and human studies support the concept of postconcussive vulnerability, showing that a second blow before the brain has recovered results in worsening metabolic changes within the cell.

- Experimental evidence suggests the concussed brain is less responsive to usual neural activation and when premature cognitive or physical activity occurs before complete recovery the brain may be vulnerable to prolonged dysfunction.

\section{Incidence}

- It is estimated that as many as 3.8 million concussions occur in the USA per year during competitive sports and recreational activities; however, as many as $50 \%$ of the concussions may go unreported.

- Concussions occur in all sports with the highest incidence in football, hockey, rugby, soccer and basketball.

\section{Risk factors for sport-related concussion}

- A history of concussion is associated with a higher risk of sustaining another concussion.

- A greater number, severity and duration of symptoms after a concussion are predictors of a prolonged recovery.
- In sports with similar playing rules, the reported incidence of concussion is higher in female athletes than in male athletes.

- Certain sports, positions and individual playing styles have a greater risk of concussion.

- Youth athletes may have a more prolonged recovery and are more susceptible to a concussion accompanied by a catastrophic injury.

- Preinjury mood disorders, learning disorders, attentiondeficit disorders (ADD/ADHD) and migraine headaches complicate diagnosis and management of a concussion.

\section{Diagnosis of concussion}

- Concussion remains a clinical diagnosis ideally made by a healthcare provider familiar with the athlete and knowledgeable in the recognition and evaluation of concussion.

- Graded symptom checklists provide an objective tool for assessing a variety of symptoms related to concussions, while also tracking the severity of those symptoms over serial evaluations.

- Standardised assessment tools provide a helpful structure for the evaluation of concussion, although limited validation of these assessment tools is available.

\section{'Sideline' evaluation and management}

- Any athlete suspected of having a concussion should be stopped from playing and assessed by a licenced healthcare provider trained in the evaluation and management of concussions.

- Recognition and initial assessment of a concussion should be guided by a symptoms checklist, cognitive evaluation (including orientation, past and immediate memory, new learning and concentration), balance tests and further neurological physical examination.

- While standardised sideline tests are a useful framework for examination, the sensitivity, specificity, validity and reliability of these tests among different age groups, cultural groups and settings is largely undefined. Their practical usefulness with or without an individual baseline test is also largely unknown.

- Balance disturbance is a specific indicator of a concussion, but not very sensitive. Balance testing on the sideline may be substantially different than baseline tests because of differences in shoe/cleat-type or surface, use of ankle tape or braces, or the presence of other lower extremity injury.

- Imaging is reserved for athletes where intracerebral bleeding is suspected.

- There is no same day RTP for an athlete diagnosed with a concussion.

- Athletes suspected or diagnosed with a concussion should be monitored for deteriorating physical or mental status. 


\section{Neuropsychological testing}

- Neuropsychological (NP) tests are an objective measure of brainbehaviour relationships and are more sensitive for subtle cognitive impairment than clinical exam.

- Most concussions can be managed appropriately without the use of NP testing.

- Computerised neuropsychological (CNP) testing should be interpreted by healthcare professionals trained and familiar with the type of test and the individual test limitations, including a knowledgeable assessment of the reliable change index, baseline variability and false-positive and falsenegative rates.

- Paper and pencil NP tests can be more comprehensive, test different domains and assess for other conditions which may masquerade as or complicate assessment of concussion.

- NP testing should be used only as part of a comprehensive concussion

management strategy and should not be used in isolation.

- The ideal timing, frequency and type of NP testing have not been determined.

- In some cases, properly administered and interpreted NP testing provides an added value to assess cognitive function and recovery in the management of sports concussions.

- It is unknown if use of NP testing in the management of sports concussion helps prevent recurrent concussion, catastrophic injury or longterm complications.

- Comprehensive NP evaluation is helpful in the post-concussion management of athletes with persistent symptoms or complicated courses. Return to class

- Students will require cognitive rest and may require academic accommodations such as reduced workload and extended time for tests while recovering from a concussion.

\section{Return to play}

- Concussion symptoms should be resolved before returning to exercise.

- A RTP progression involves a gradual, step-wise increase in physical demands, sports-specific activities and the risk for contact.

- If symptoms occur with activity, the progression should be halted and restarted at the preceding symptom-free step.

- RTP after concussion should occur only with medical clearance from a licenced healthcare provider trained in the evaluation and management of concussions.

\section{Short-term risks of premature RTP}

- The primary concern with early RTP is decreased reaction time leading to an increased risk of a repeat concussion or other injury and prolongation of symptoms.

\section{Long-term effects}

- There is an increasing concern that head impact exposure and recurrent concussions contribute to long-term neurological sequelae.

- Some studies have suggested an association between prior concussions and chronic cognitive dysfunction. Large-scale epidemiological studies are needed to more clearly define risk factors and causation of any long-term neurological impairment.

\section{Disqualification from sport}

- There are no evidence-based guidelines for disqualifying/retiring an athlete from a sport after a concussion. Each case should be carefully deliberated and an individualised approach to determining disqualification taken.

\section{Education}

- Greater efforts are needed to educate involved parties, including athletes, parents, coaches, officials, school administrators and healthcare providers to improve concussion recognition, management and prevention.

- Physicians should be prepared to provide counselling regarding potential long-term consequences of a concussion and recurrent concussions.

\section{Prevention}

- Primary prevention of some injuries may be possible with modification and enforcement of the rules and fair play.

- Helmets, both hard (football, lacrosse and hockey) and soft (soccer, rugby) are best suited to prevent impact injuries (fracture, bleeding, laceration, etc.) but have not been shown to reduce the incidence and severity of concussions.

- There is no current evidence that mouth guards can reduce the severity of or prevent concussions.

- Secondary prevention may be possible by appropriate RTP management.

Legislation

- Legislative efforts provide a uniform standard for scholastic and nonscholastic sports organisations regarding concussion safety and management.

\section{Future directions}

- Additional research is needed to validate current assessment tools, delineate the role of NP testing and improve identification of those at risk of prolonged post-concussive symptoms or other long-term complications. - Evolving technologies for the diagnosis of concussion, such as newer neuroimaging techniques or biological markers, may provide new insights into the evaluation and management of sports concussion.

\section{BACKGROUND AND PURPOSE}

The recognition and management of concussions in sports is an evolving and controversial topic with a myriad of groups and organisations producing statements and recommendations. ${ }^{1-6}$ The purpose of this statement is to provide an evidence-based, best practises summary to assist physicians with the evaluation and management of sports-related concussion and to establish the level of evidence, knowledge gaps and areas requiring additional research. The American Medical Society for Sport Medicine (AMSSM) represents over 2100 non-surgical sports medicine physicians who have completed additional training in sports medicine after a residency programme in family medicine, internal medicine, paediatrics, emergency medicine or physical medicine and rehabilitation, many who have extended expertise in concussion evaluation and management.

Sports medicine physicians are frequently involved in the care of patients with sports concussion and are specifically trained to provide care along the continuum of sports concussion from the acute injury to return-to-play (RTP) decisions. The care of athletes with sports-related concussions is ideally performed by healthcare professionals with specific training and experience in the assessment and management of concussions. Competence should be determined by training and experience, not dictated by specialty. While this statement is directed towards sports medicine trained physicians, it may also be used by other physicians and healthcare professionals to improve the care of patients with sports-related concussions.

\section{LEVEL OF EVIDENCE}

This statement uses the strength-of-recommendation taxonomy (SORT) to grade recommendations based on athlete outcomes (table 1). ${ }^{7}$

\section{DEFINITION OF A CONCUSSION}

A concussion is defined as a traumatically induced transient disturbance of brain function and is caused by a complex pathophysiological process. Concussions have also been referred to as mild traumatic brain injuries (MTBI). While all concussions are 
Table 1 Strength-of-recommendation taxonomy

\begin{tabular}{ll}
\hline $\begin{array}{l}\text { Strength of } \\
\text { recommendation }\end{array}$ & Basis for recommendation \\
\hline A & Consistent, good-quality patient-oriented evidence \\
B & Inconsistent or limited-quality patient-oriented evidence \\
C & Consensus, disease-oriented evidence, usual practise, \\
& $\begin{array}{l}\text { expert opinion or case series for studies of diagnosis, } \\
\text { treatment, prevention or screening }\end{array}$ \\
\hline
\end{tabular}

MTBIs, not all MTBIs are concussions. Concussions are a subset of MTBIs, on the less-severe end of the brain injury spectrum and are generally self-limited in duration and resolution.

\section{PATHOPHYSIOLOGY}

Concussions occur when linear and/or rotational forces are transmitted to the brain. Currently, there is no known biomechanical threshold for a clinical concussion. A demonstrated cellular process, the 'neurometabolic cascade' underlying the clinical presentation of a concussive injury describes a complex cascade of ionic, metabolic and pathophysiological events that is accompanied by microscopic axonal injury. ${ }^{8-10}$ This disruption of ionic balance and normal metabolism requires energy to re-establish homeostasis. However, the need for increased energy occurs in the presence of decreased cerebral blood flow and ongoing mitochondrial dysfunction, resulting in an imbalance of energy supply and demand. ${ }^{8} 1011$ Until normal brain cellular function is restored, animal and human studies support the concept of increased postconcussive vulnerability, showing that a second injury before the brain has recovered results in worsening cellular metabolic changes and more significant cognitive deficits. ${ }^{8} 911-16$ Experimental evidence further suggests the concussed brain is less responsive to physiological neural activation. ${ }^{9}{ }^{10}$ Thus, excessive cognitive or physical activity before complete recovery may result in prolonged dysfunction. Some of these pathophysiological perturbations are more pronounced in youth, raising concerns that the immature brain may be even more susceptible to repeat concussions before complete recovery. ${ }^{9}$

\section{REPORTED INCIDENCES OF SPORTS-RELATED CONCUSSIONS}

Concussions occur commonly both in helmeted and nonhelmeted sports, and recent data suggest a trend of increased annual concussion rates over the past decade. ${ }^{17}{ }^{18}$ Reasons for the apparent increased incidences are unknown, but it is widely speculated to be a result of the emphasis on concussion education and awareness leading to increased identification and reporting. ${ }^{17}{ }^{18}$ Despite the increased reported incidence of concussion in recent years, there has not been a corresponding increase in the incidence of sports-related catastrophic brain injuries such as subdural and epidural haematomas, or malignant cerebral oedema (ie, second impact syndrome (SIS)).

The Centers for Disease Control and Prevention (CDC) estimates that between 1.6 and 3.8 million sports-related concussive injuries occur annually in the USA ${ }^{19}$ and account for 5-9\% of all sports-related injuries. ${ }^{20} 21$ Thirty per cent of all concussions in individuals between 5 and 19 years of age are sports-related and result in a significant number of emergency room visits. ${ }^{6} 22$ The majority of concussions occurring in organised sports in the USA are sustained in football, wrestling, girls' soccer, boys'

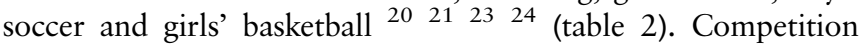

Table 2 Concussion rates per 1000 athlete exposures

\begin{tabular}{|c|c|c|c|c|c|c|}
\hline Sport & $\begin{array}{l}\text { Powell } \\
1999\end{array}$ & $\begin{array}{l}\text { Schultz } \\
2004\end{array}$ & $\begin{array}{l}\text { Hootman } \\
2007\end{array}$ & $\begin{array}{l}\text { Gessel } \\
2007\end{array}$ & $\begin{array}{l}\text { Lincoln } \\
2011\end{array}$ & $\begin{array}{l}\text { Marar } \\
2012\end{array}$ \\
\hline Level & $\begin{array}{l}\text { High } \\
\text { school }\end{array}$ & $\begin{array}{l}\text { High } \\
\text { school }\end{array}$ & College & $\begin{array}{l}\text { High } \\
\text { school }\end{array}$ & $\begin{array}{l}\text { High } \\
\text { school }\end{array}$ & $\begin{array}{l}\text { High } \\
\text { school }\end{array}$ \\
\hline $\begin{array}{l}\text { Years } \\
\text { studied }\end{array}$ & $\begin{array}{l}1995- \\
1997\end{array}$ & $\begin{array}{l}1996- \\
1999\end{array}$ & $\begin{array}{l}1988- \\
2004\end{array}$ & $\begin{array}{l}2005- \\
2006\end{array}$ & $\begin{array}{l}1997- \\
2008\end{array}$ & $\begin{array}{l}2008- \\
2010\end{array}$ \\
\hline Baseball & 0.05 & 0.11 & 0.07 & 0.05 & 0.06 & 0.05 \\
\hline Softball & 0.10 & 0.10 & 0.14 & 0.07 & 0.11 & 0.16 \\
\hline $\begin{array}{l}\text { Boys' } \\
\text { basketball }\end{array}$ & 0.11 & 0.10 & 0.16 & 0.07 & 0.10 & 0.16 \\
\hline $\begin{array}{l}\text { Girls' } \\
\text { basketball }\end{array}$ & 0.16 & 0.17 & 0.22 & 0.21 & 0.16 & 0.21 \\
\hline $\begin{array}{l}\text { Boys' } \\
\text { soccer }\end{array}$ & 0.18 & 0.23 & 0.28 & 0.22 & 0.17 & 0.19 \\
\hline $\begin{array}{l}\text { Girls' } \\
\text { soccer }\end{array}$ & 0.23 & 0.13 & 0.41 & 0.36 & 0.35 & 0.34 \\
\hline Football & 0.59 & 0.33 & 0.37 & 0.47 & 0.60 & 0.64 \\
\hline $\begin{array}{l}\text { Field } \\
\text { hockey }\end{array}$ & 0.09 & NR & 0.18 & NR & 0.10 & 0.22 \\
\hline Volleyball & 0.02 & NR & 0.09 & 0.05 & NR & 0.06 \\
\hline Wrestling & 0.25 & 0.09 & 0.25 & 0.18 & 0.17 & 0.22 \\
\hline Ice hockey & & & 0.41 & & & 0.54 \\
\hline Overall & & 0.17 & 0.28 & 0.43 & 0.24 & 0.24 \\
\hline
\end{tabular}

NR, not reported.

concussion rates are consistently higher than practise rates, and in high school and college sports with the same rules (basketball and soccer) there is an increased incidence of concussions reported in female athletes. ${ }^{20} 2325$ Several studies contend the true incidence is likely higher than that documented because many athletes fail to report concussions. ${ }^{26-28}$ With a greater focus on concussion awareness and state legislation, the reported incidence is likely to continue to increase.

\section{SIGNS AND SYMPTOMS}

There are many signs and symptoms of a concussion that can be observed (box 1). Headache is the most commonly reported symptom with dizziness, the second most common. 6252930 Loss of consciousness only occurs in about $10 \%$ of concussions. 5 6 630 31-34 Several symptoms of concussion are nonspecific; for example, nausea, vomiting and headache are a common presentation of acute gastroenteritis, and dizziness is a common symptom of acute cardiac compromise. Some symptoms overlap with other disorders such as sleep disturbances, depression and attention deficit disorder (ADD) and it is helpful to determine whether these symptoms were present prior to the injury (level of evidence C). In college athletes, 59\% reported concussion-like symptoms in the prior year with no history of head injury and 50-84\% of high-school athletes reported similar symptoms of concussion at baseline testing. ${ }^{34-36}$ There have been no consistently demonstrated differences in the symptoms reported between male and female athletes. ${ }^{34-39}$

Most studies report that $80-90 \%$ of athletes have symptom resolution by 7 days following their injury, ${ }^{6} 25293239$ although symptom resolution may not always indicate a complete cognitive recovery as persistent deficits may be present on neuropsychological (NP) testing. ${ }^{32}{ }^{40}$ However, the clinical importance of persistent NP testing changes in the absence of continued symptoms is unknown. 


\section{Box 1 Signs and symptoms of a concussion}

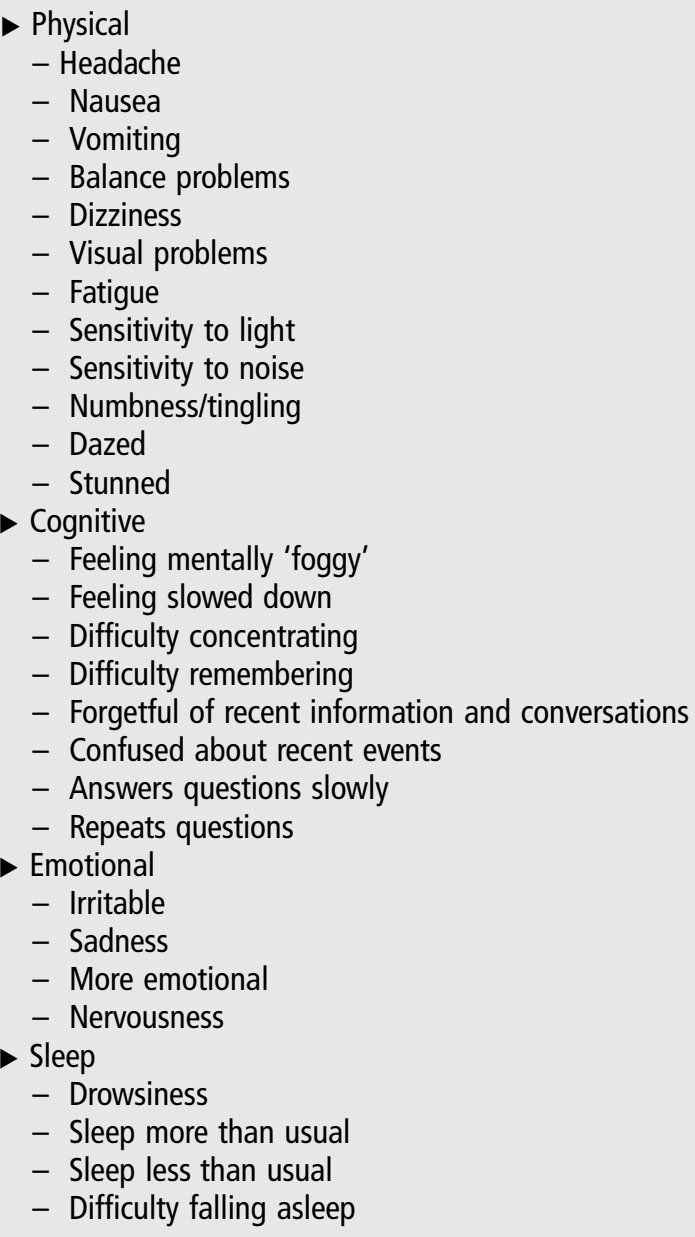

\section{RISK FACTORS/MODIFIERS FOR SPORTS-RELATED CONCUSSIONS}

A history of prior concussion, a greater number, severity or duration of symptoms after a concussion, female sex, genetic predisposition, a history of a learning disorder, ADD, migraines or mood disorder, and playing certain positions have all been suggested to affect the risk of sustaining a concussion or having a more protracted course.

\section{Previous concussion}

A history of concussion is associated with a 2-5.8 times higher risk of sustaining another concussion. ${ }^{24} 3841-46$ Athletes with a prior history of concussion may also report more symptoms at baseline than those without a history of concussion. ${ }^{36}{ }^{47-49}$ However, there is conflicting evidence on whether a prior concussion is associated with a prolonged recovery course. ${ }^{50}{ }^{51}$ Lau found no difference in the history of concussion and time to recover, while Slobounov demonstrated significantly slower recovery rates of neurological functions after a second concussion. ${ }^{50}{ }^{51}$ As with other sports injuries, the greatest risk factor for concussion is a previous concussion, and progressively prolonged symptoms with subsequent concussions is a concerning prognostic sign.

\section{Number, severity and duration}

A greater number, severity and duration of symptoms after a concussion are predictors of a prolonged recovery. ${ }^{47}$ 51-53
Specific signs or symptoms may also predict recovery time. Dizziness at the time of injury was found to be the greatest predictor in high-school football players for a recovery taking longer than 21 days, ${ }^{50} 54$ and athletes who had more symptoms in the cognitive or migraine symptoms clusters often required more recovery time.$^{50}$ In rugby players, headaches lasting longer than $60 \mathrm{~h}$, three or more symptoms at initial presentation, and the presence of fatigue/tiredness/fogginess were associated with a longer recovery. ${ }^{29}$

\section{Sex}

Recent data suggest that in sports with similar rules female athletes sustain more concussions than their male counterparts. $^{20} 23255556$ In addition, female athletes experience or report a higher number and severity of symptoms as well as a longer duration of recovery than male athletes in several studies. ${ }^{38}{ }^{55-59}$ A decreased head-neck segment mass of female athletes compared to male athletes may contribute to greater angular acceleration of the head after a concussive impact as a mechanism for more severe injury. ${ }^{60}$ Oestrogen and differential cerebral blood flow may also play a role in influencing concussion severity and outcome. ${ }^{15}{ }^{61} \mathrm{~A}$ further study is needed to understand if sex is a risk factor for concussion and what mechanisms may account for it, or if sex is merely a predictor of symptom reporting. ${ }^{62}$

\section{Age}

Youth athletes may have a more prolonged recovery and are more susceptible to concussions accompanied by a catastrophic injury. The developing brain differs physiologically from the adult brain when comparing the brain water content, degree of myelination, blood volume, blood-brain barrier, cerebral metabolic rate of glucose, blood flow, number of synapses and geometry and elasticity of the skull's sutures. ${ }^{63}$ Developmentally younger brains have less-established engrams and may have less-cognitive reserve than more mature brains. ${ }^{94}$ This may account for the demonstrated increase in time to recovery from concussions seen in younger athletes. ${ }^{65-68}$ It is difficult to compare studies at different levels of play (high school, college and professional) as longer recovery times could reflect differences in study methodology, in risk tolerance and RTP protocols, or all of the above. Recovery patterns have not been adequately studied in athletes less than 15 years old. Catastrophic injury is more likely in younger athletes and is hypothesised to be related to the physiological differences between younger and older brains. ${ }^{69-71}$

\section{Sport, position and style of play}

Certain sports, positions and individual playing styles have a greater risk of concussion. The rate of concussion also varies by the level of play. Position and style of play also appear to affect the risk of concussion. Mechanisms of concussive injury may vary based on the sport as well as the level of play. The most common mechanism of a concussion is by way of a player-to-player contact. ${ }^{25}$ It is not surprising; therefore, that sports and positions involved in frequent collisions' impacts sustain more concussions. Studies on professional football players have shown that 'backs' (quarterbacks, wide receivers, running backs and defensive backs) have a three times greater risk of concussion than 'linemen', ${ }^{72}$ and kickoffs had a four times higher risk of concussions than rushing or passing plays. ${ }^{72}$ In high-school football players, linebackers were the most commonly concussed on the defence and running backs on the offence. In soccer players, concussions most commonly occur from player contact both at the high-school level and at the 
college level. ${ }^{73-75}$ At the high-school level, one study demonstrated that $25.3 \%$ of concussions were associated with illegal activity. In a prospective study of college soccer players, the mechanism of concussion was again primarily player contact and importantly none were related to purposeful heading. ${ }^{76}$ In hockey, the most common mechanism of a concussive injury is checking.

\section{Genetics}

Studies on the association between concussions and genetic polymorphisms such as APOE e4 (apolipoprotein e4), APOE G-219T promoter or tau exon 6 are limited by small sample sizes, limited sports populations, retrospective study design, use of self-reported concussion history and a lack of control groups. ${ }^{77} 78$ Some studies have suggested potential associations but methodological weaknesses do not support definitive conclusions. A study of college athletes showed a prior self-reported concussion was associated with increased odds of having either one APOE e4 allele or at least one APOE G-219T 'T' allele. In other reports, a cross-sectional study showed college athletes with a self-reported history of concussions were 2.7 times as likely to have APOE promoter G-219T 'TT' genotype after controlling for various cofounders, ${ }^{77}$ and a small prospective cohort study showed no significant association between genotype and concussion risk. ${ }^{46}$

The largest prospective cohort study available $(n=234$ athletes with 45 prospective concussions) showed no significant association between APOE, APOE G-219T, Tau exon 6 Hist $^{46} \mathrm{Tyr}$ and Tau exon 6 Ser $^{52}$ Pro and concussion risk, although Tau exon 6 Ser ${ }^{52}$ Pro was trending towards significance $(p=0.09) .{ }^{79}$ A large prospective cohort study of a representative athletic population that controls for athletic exposure, prior concussion history and other predisposing factors is necessary to determine if polymorphisms confer an increased risk for concussion, more severe concussions or delayed neurocognitive recovery.

\section{Mood disorders}

Mood disorders, either pre-existing or as a result of a concussive episode, complicate both diagnosis and management of concussion. Symptoms of anxiety, depression or irritability occur in $17-46 \%$ of high-school and college athletes and affect the brain's mood centres, including the hippocampus, amygdala and prefrontal brain regions which are also affected in concussion. ${ }^{8081}$ There is no evidence that the pre-existence of mood disorders predispose athletes to concussion. However, when evaluating an athlete it is often difficult to determine which symptoms preceded the concussion, which have been caused by the concussion, and which symptoms are worsened after the concussion. An increased incidence of depression has been associated with a history of concussion among retired boxers and professional football players, however, these retrospective studies relied on a self-reported history and did not control for other factors that may cause depression. ${ }^{42}$ Anxiety, depression and other psychological impairments may also affect NP testing, either at baseline or at repeat testing; complicating test interpretations. ${ }^{83}{ }^{84}$ Knowing preinjury mood status may be beneficial to the evaluation of athletes with a subsequent injury (level of evidence C).

\section{Learning disabilities and attention disorders}

As with other conditions which share common symptomatology with a concussion, it is important to take learning disorders into account in both diagnosis and management of a concussion. Preinjury learning disabilities and ADD/ADHD may be associated with increased cognitive dysfunction and prolonged recovery after a concussion. Collins et $a l^{85}$ found that athletes with learning disabilities and a history of concussion did proportionally worse on selected paper and pencil NP testing than those without any learning disabilities. In 108 athletes with concussions, Lau found there was no association between learning disability or ADD and protracted recovery. ${ }^{548687}$ Learning and attention disorders share common features of concussions such as difficulty with memory, attention and concentration making the diagnosis and management in these individuals more challenging. Baseline NP testing scores are lower in those with learning and attention disabilities ${ }^{85} 88$ independent of the concussion history making baseline testing more important in those with learning or attention disorders if NP testing is going to be used postinjury to assist in RTP decisions.

\section{Migraines}

A history of pre-existing migraine headaches may be a risk factor for a concussion and may be associated with a prolonged recovery. Only $2.9 \%$ of NCAA college basketball athletes $(0.9 \%$ of men and $4.4 \%$ of women) and $22 \%$ of Australian Rules football players report migraines meeting International Headache Society criteria for diagnosis compared to $10 \%$ of the general population. ${ }^{89-91}$ An association between a concussion and preexisting migraine was shown in one retrospective population study, ${ }^{92}$ but no association between a pre-existing migraine and prolonged course of concussion has been demonstrated. ${ }^{548687}$

A concussion can trigger a post-traumatic migraine and athletes with postconcussion migraine usually have more symptoms and poorer performance upon NP tests than athletes with other types of headache or no headache at all. ${ }^{93}$ In addition, Lau found that athletes (without pre-existing diagnosis of migraines) who developed symptoms in the 'migraine symptoms complex' which included headaches, visual problems, dizziness, noise/ light sensitivity, nausea/vomiting, balance problems and numbness/tingling had a more protracted recovery. ${ }^{54}$ Similar to mood, learning and attention disorders, it is important to understand preinjury cognitive or psychological disorders to optimise management.

\section{MANAGEMENT OF CONCUSSIONS \\ Preseason}

Preparation for the care of concussed athletes begins prior to any practise or competition with a preparticipation exam (PPE) and the development of an emergency action plan (level of evidence C). The PPE should include concussion-related questions including a past history of concussion (number, frequency, severity and recovery) and the presence of mood, learning, attention or migraine disorders ${ }^{94}$ (level of evidence C). This information can be used to assess risk and for historical reference in the case of injury.

The exact role and impact on concussion management of baseline testing remains unclear, as no study has shown that use of these tests provides better short-term or long-term outcomes for athletes with concussions. The preseason evaluation may also include baseline symptom scores, baseline balance testing, a baseline sideline evaluation tool (SCAT2, NFL Sideline Concussion Assessment Tool) and/or baseline computerised neuropsychological (CNP) testing. This baseline testing may be more important in high-risk athletes with a prior history of concussions, with confounding conditions (learning disability, mood and attention disorders, migraine headaches) and sports with a higher incidence of concussions ${ }^{95} 96$ (level of evidence C). 
The reliability of preseason testing as a dependable baseline assessment to compare with postinjury testing performed weeks or months later is also controversial and for many tests unknown. While baseline testing is increasingly used in practise and may have a role in the preseason evaluation of high-risk athletes, the role of baseline tests in other settings is unknown ${ }^{97}$ (level of evidence C). More research is needed to define which baseline tests should be performed and in which athletes.

Preseason testing requires an honest effort on the part of an athlete. Balance testing is time intensive, but can be done by a non-physician personnel. Computerised NP testing requires adequate resources and a quiet environment for best results, but can be done in large groups. NP testing does require health professionals who are competent in test interpretation.

\section{On-field management}

The first step in assessing a collapsed athlete is to check for his/ her airway, breathing and heart function, followed by a physical evaluation to exclude a cervical spine injury and/or more serious brain injury (level of evidence C). If a cervical spine injury cannot be eliminated, neck immobilisation and immediate transfer to the emergency department capable of advanced neurological imaging and management of cervical trauma should follow (level of evidence C). Emergency transfer should also occur if there are signs of a more serious brain injury such as deteriorating mental status, focal neurological findings (abnormal or unequal pupil reaction, abnormalities with extraocular movements, abnormalities on a screening motor/sensory exam) or worsening of symptoms (level of evidence C). If cervical spine and more serious brain injury can be excluded with a history and physical exam, then a more detailed history of injury and an examination that includes symptoms, cognitive and balance assessment and neurological examination to evaluate for concussion may be initiated on site (level of evidence C).

\section{Sideline assessment of a concussion}

Any athlete suspected of having a concussion should be stopped from play and assessed by a licenced healthcare provider trained in the evaluation and management of concussions (level of evidence C). It is useful to utilise a standardised approach in evaluating the athlete post injury. A physical exam is primarily to rule out more serious brain injury and assess balance. History, cognitive testing and balance testing comprise the majority of the evaluation. Previous medical history is important to understand confounding factors that may be present, such as mood or attention disorders, or orthopaedic injury, which may affect the physical examination.

There have been several different sideline concussion assessment tools developed, and in some settings the use of these tools is required. Standardised measures are designed to reduce the degree of subjectivity encountered by medical providers responsible for making a rapid and precise injury assessment and concussion diagnosis decision. When possible, sideline tests can be compared to a reliable preinjury baseline (level of evidence C). Baseline values of commonly used sideline tests can vary widely from athlete to athlete, and the results depend on age, sport, sex and confounding medical conditions, making the use of sideline tests without baseline results difficult. ${ }^{35} 365998$ In addition, baseline tests may change as part of the normal maturation and developmental process and can be dependent on current mood, fatigue and other factors. Familiarity with an athlete is an important component in the sideline evaluation of a concussion, given the variability in presentation (level of evidence C).

The most common sideline measures include the use of symptoms scores, the Maddocks Questions, the Standardized Assessment of Concussion (SAC) and the Balance Error Scoring System (BESS) or modified BESS. The Sport Concussion Assessment Tool 2 (SCAT2) and the NFL Sideline Concussion Assessment Tool combine various assessment measures to give one score. The sensitivity and specificity of the diagnosis of concussion may increase when combining multiple assessment tools. $^{86}$

The sensitivity (the likelihood that an athlete with concussion will be correctly identified), specificity (the likelihood that an athlete without a concussion will be correctly classified), the false-positive and false-negative rates vary for the different sideline tests and are important to be considered in the evaluation of an athlete (table 3). The sensitivity and specificity of these tests may also change over the course of a concussion. A tool which is appropriate for sideline use may not be appropriate for office use. For example, balance testing typically returns to

Table 3 Sideline concussion evaluation tests

\begin{tabular}{|c|c|c|c|c|c|}
\hline Test & $\begin{array}{l}\text { Time to } \\
\text { administer }\end{array}$ & Sensitivity & Specificity & $\begin{array}{l}\text { False } \\
\text { positives }\end{array}$ & $\begin{array}{l}\text { False } \\
\text { negatives }\end{array}$ \\
\hline Symptom scores & $2-3 \min$ & & & & \\
\hline Broglio (2007) 9-item & & $68 \%$ & & & $32 \%$ \\
\hline McCrea (2005) 17-item & & $89 \%$ & $100 \%$ & $0 \%$ & $11 \%$ \\
\hline Maddocks & $<1 \min$ & & & & \\
\hline (CJSM 1995) & & $32-75 \%$ & $86-100 \%$ & $29-68 \%$ & $0-11 \%$ \\
\hline SAC & $5 \mathrm{~min}$ & & & & \\
\hline Barr (2001) & & $94 \%$ & $76 \%$ & $24 \%$ & $6 \%$ \\
\hline McCrea (2005) & & $80 \%$ & $91 \%$ & $9 \%$ & $20 \%$ \\
\hline BESS & $5 \min$ & & & & \\
\hline (McCrea 2005) & & $34 \%$ & $91 \%$ & $66 \%$ & $9 \%$ \\
\hline Modified BESS & $2-3 \min$ & Unknown & Unknown & Unknown & Unknown \\
\hline $\mathrm{SAC}+\mathrm{BESS}$ & $10 \min$ & Unknown & Unknown & Unknown & Unknown \\
\hline NFL Sideline Concussion Assessment Tool (SAC+modified BESS+Symptoms score) & $8-10 \min$ & Unknown & Unknown & Unknown & Unknown \\
\hline $\begin{array}{l}\text { SCAT2 (SAC+modified BESS+Glasgow coma scale+physical signs score+Maddock's } \\
\text { score+coordination exam }\end{array}$ & $8-10 \min$ & Unknown & Unknown & Unknown & Unknown \\
\hline
\end{tabular}


normal after 3 days making it a potentially useful sideline test but not as useful for a later follow-up. With our current sideline tests, as sensitivity goes up, the specificity goes down, so some athletes without a concussion may be held from RTP. Physicians evaluating concussions on the sideline are encouraged to err on the side of safety-'when in doubt sit them out'. More research is needed to validate and improve sideline testing.

\section{Balance testing}

Over the past decade, the use of balance testing has become increasingly utilised in the diagnosis and management of sportsrelated concussions particularly on the sideline. Studies have identified temporary or permanent deficits in static and/or dynamic balance in individuals with mild-to-moderate traumatic brain injury (TBI) ${ }^{99-102}$ and similar balance deficits have been reported in sports-related concussions. ${ }^{32} 82$ 103-105

\section{Balance error scoring system}

The test is easy-to-administer in 5-7 min and is inexpensive. Three stances (a narrow double-leg stance; single-leg stance and tandem stance) and two footing surfaces (a firm surface/floor or medium density foam) are used for the complete test. Each stance is held, with hands on hips and eyes closed, for $20 \mathrm{~s}$. 'Error' point deductions are given for specific behaviours, including opening eyes, lifting hands off hips, stepping, stumbling or falling. There is a maximum score of 60 points if both floor surfaces are used, or 30 if only one surface is used.

McCrea et al ${ }^{103}$ reported that BESS scores in concussed college football players varied from baseline an average of -5.7 points, when measured immediately following the game or practise in which the injury occurred. Changes in BESS performance and rapid recovery of static balance have been reported in other studies of concussed athletes. ${ }^{105-107}$ For most athletes, BESS performance returned to preseason baseline levels (average 12 errors) by 3-7 days postinjury. Sensitivity values for the BESS are reported as the highest at the time of injury (sensitivity $=0.34$ ). Specificity values for this instrument ranged from 0.91 to 0.96 across postinjury days $1-7 .{ }^{32}$ One study questioned the clinical utility of the BESS suggesting it has low interrater and intrarater reliabilities, and that the minimum detectible change for the total BESS score is between 7 and 9 points making its clinical use questionable. ${ }^{108}$ Another study showed $42 \%$ of players without a clinically diagnosed concussion exceeded the reliable change on the BESS when examined after a game. ${ }^{109}$

Both the SCAT2 and the NFL Sideline Concussion Assessment Tool utilise a modified BESS. The modified BESS only includes testing on a firm surface and does not include testing on a medium-density foam. There are no reported intrarater or inter-rater reliability studies using the modified BESS, no established minimal clinically meaningful change, and no sensitivity and specificity values available. In addition there are practical issues with using the BESS in a sideline setting. Baseline testing is typically done in a training room on a firm surface in sneakers without tape, or ankle braces. Sideline testing is typically done in cleats with ankles taped or braced on grass or turf field. Despite these limitations, balance is often affected by a concussion and should be evaluated when a concussion is suspected. Ideally baseline BESS testing should be done in 'game' conditions (level of evidence C). More research to refine sideline balance testing is warranted.

The Sensory Organization Test (SOT) (NeuroCom International, Inc, Clackamas, Oregon, USA) is a technical force plate system used for assessing balance following a concussion, but is the gold standard in balance testing in research studies and clinical availability is limited. The SOT has proven to be a useful tool for detecting sensory interaction and balance deficits following a concussion. ${ }^{43} 104105110111$ Research utilising the SOT has identified deficits lasting an average of 3 days postinjury, similar to the studies involving clinical balance tests. ${ }^{104} 106$ These studies indicate that the regions of the brain responsible for coordinating the sensory modalities (thalamus and its interconnective pathways to the cerebral cortex) may be disrupted postinjury and that the vestibular system is often affected following a concussion. ${ }^{97} 99$

\section{Sideline management and disposition}

When a player is being evaluated for or has been diagnosed with a concussion, it is a good safety strategy to sequester an essential piece of playing equipment to avoid an 'inadvertent' return to the game. A concussed player should not be left alone if the decision is made to keep the player on site, and regular monitoring for deteriorating physical or mental status is essential (level of evidence C). If after a complete sideline assessment a concussion is not thought to have occurred and the player is allowed to continue to play, serial evaluation should be performed after return to the game to ensure the decision was correct (level of evidence C).

Athletes diagnosed with a concussion should not RTP on the same day of practise or competition (level of evidence C). Athletes with a concussion need appropriate disposition to home, to remain onsite until the end of the contest, or if needed transfer to an emergency facility. This is not always an easy or straightforward decision and regular re-evaluation is desirable until a final disposition is determined. The medical provider should arrange or discuss the follow-up evaluation with a parent/guardian or in loco parentis representative for minor participants. The medical provider should also arrange for the athlete to be accompanied or monitored once allowed to leave the competition area. 'Take-home' information, ideally in a written form, should be discussed with the athlete and any accompanying party including signs or symptoms that should prompt an emergency room evaluation, avoiding any physical or cognitive exertion that can worsen or mimic signs of a concussion, avoiding alcohol and when to be seen in a follow-up (level of evidence C).

Common advice previously given to those with a concussion include frequent awakening of the concussed athlete to 'make sure they are okay' is no longer recommended. If level of consciousness is a concern, the athlete should be imaged and observed in a hospital setting, otherwise sleep should not be interrupted as it is likely restorative. Caretakers should be informed that it is desirable to let the athlete sleep. Likewise, no data support that postinjury use of anticoagulation increases morbidity or mortality in head trauma; ${ }^{12-114}$ however, because of the theoretical risk of bleeding, aspirin and NSAIDs are generally avoided postconcussion.

\section{Postsideline and office management of concussions} Follow-up evaluation and treatment

Athletes with concussion should have medical follow-up (level of evidence C). A detailed history of the event mechanism, course of symptoms and previous history of concussion should be elicited. Serial monitoring of standardised symptoms scores can be helpful to more objectively assess resolution of symptoms or return to their preinjury baseline. In the vast majority of concussions balance disturbances are back to baseline by 3 days. ${ }^{105-107}$ Worsening symptoms, pronounced amnesia, progressive balance 
dysfunction or focal neurological deficits on examination could be signs of intracranial pathology and should prompt neurological imaging (level of evidence $\mathrm{C}$ ).

The treatment of a concussion consists of relative physical and cognitive rest. In the early stages of a concussion recovery, an athlete should not engage in physical or cognitive activities that result in an increase in symptoms (level of evidence B).

\section{NP testing}

NP testing in athletes began in the 1980s and its use has expanded in the last decade with the availability of computerised testing. ${ }^{2}{ }^{115-117}$ Data suggest that cognitive impairment after concussion may last longer than subjective symptoms. NP testing is a tool that can identify occult cognitive impairment and may also aid in documenting an athlete's recovery from a concussive injury. $^{2} 529$ 116-120 Although variable by different test type, several domains of cognitive function are evaluated, focusing on those areas most affected by concussion such as memory, cognitive processing speed and reaction time. ${ }^{117}{ }^{121} \mathrm{It}$ is currently unknown if the use of NP testing alters the shortterm risks (recurrence or catastrophic injury) or potential longterm complications. ${ }^{122} 123$

There are two main types of testing employed: paper and pencil and computerised. Paper and pencil tests are typically administered and interpreted by a neuropsychologist. ${ }^{2}{ }^{115}$ These tests are more comprehensive and have the advantage of testing additional domains, which may identify other conditions masquerading as a concussion or postconcussive syndrome. ${ }^{121}$ However, paper and pencil testing is more expensive and requires significantly more time to administer. ${ }^{117} 124 \mathrm{CNP}$ testing has advantages in the athletic setting as it is less expensive, takes less time to administer, may be administered concurrently to groups of athletes, provides instant information to the provider, has more precise measures of reaction time, has multiple forms and may be used for serial assessment. ${ }^{2} 116117$ Both paper and pencil and computerised testing have significant individual variability with regard to domains measured and performance measures such as validity, sensitivity, specificity, reliable change index and baseline variability. ${ }^{2} 121$ 124-127

Testing, particularly CNP, has been shown to have moderate sensitivity in the detection of postconcussive cognitive deficits. ${ }^{117} 118126128$ NP testing has not been validated as a diagnostic tool but has the ability to show cognitive deficits longer than athletes are symptomatic. ${ }^{2} 529$ 116-120 123 Because of this, testing has been promoted as a monitoring tool in the recovery from a concussive event. ${ }^{4}{ }^{5}$ Intuitively, baseline testing appears to have advantages over comparative normal values, but no studies have looked at this issue with regard to outcomes, and there is limited data to suggest age-related norms may be adequate to assist with management decisions. ${ }^{97} 129$ No ideal interval for repeating baseline testing has been established for NP or CNP testing. ${ }^{117} 130131$ Test-retest reliability studies of currently available NP tests show baseline testing may need to be repeated but an ideal interval has not been established. $^{98} \quad 119 \quad 125 \quad 127 \quad 132133$ Additionally, many intrinsic and extrinsic factors can affect performance on NP testing, particularly CNP testing. ${ }^{116} 130{ }^{131}$ In one study of college football players without a diagnosis of a concussion, CNP testing $48 \mathrm{~h}$ postgame showed that $75 \%$ exceeded a reliable change in one category and $25 \%$ exceeded reliable changes in two categories. ${ }^{109}$ If testing is used, care should be taken to make the baseline and postinjury physiological variables (ie, fatigue) and environmental variables (ie, distractions) as similar as possible. ${ }^{115} 116$ Other conditions such as age, effort, ${ }^{134}$ sex, cultural background, primary language, mood disorders, migraines and history of the concussion also can affect testing results. $^{2} 67 \quad 115-117 \quad 124 \quad 125 \quad 135-139$ No optimum postconcussion monitoring interval has been established and reported intervals vary from every few days to only testing asymptomatic athletes prior to return to sports. ${ }^{2} 5126$ No studies have evaluated these intervals with regard to long-term sequelae or recurrent concussive risk.

There are no universally agreed upon recommendations for use of NP testing and existing recommendations are based on experts' opinions. There are several potential reasons to consider testing. In high-risk athletes with prior concussion, testing adds additional information that may help with RTP decisions. ${ }^{4}$ In athletes who may deny symptoms to RTP sooner, testing may play a role to identify athletes with persistent deficits. ${ }^{119}$ It may also aid in the medicolegal or policy considerations in the management of these athletes.

NP testing is only an adjunct to clinical assessment and judgment (level of evidence C). In the majority of cases, concussions can be managed appropriately without the use of NP testing (level of evidence C). However, testing may have an added value in some settings, especially high-risk athletes. NP testing should be interpreted by a healthcare professional trained and familiar with the type of test and the individual limitations of each test (level of evidence C). NP testing should be used only as part of a comprehensive concussion management strategy and should not be used in isolation (level of evidence C).

\section{Symptom management}

The appropriate management of concussion symptoms requires careful consideration of the timing and natural history of the injury. In the acute setting ( $0-10 \mathrm{~h}$ post onset of injury) drugs that could alter mental status, such as benzodiazepines, should be avoided (level of evidence C). After this acute phase, medications may be considered for symptomatic relief, although those that affect the CNS, such as stimulants, certain antinausea medications and antidepressants, should be used with caution as they may cloud the neurological and cognitive examination and impair the physician's ability to assess the injury (level of evidence C). When the patient is being considered for return-to-participation, medications that may mask symptoms of a concussion must be avoided. During the entire course of the injury, activities and environmental conditions that exacerbate symptoms should be moderated appropriately.

There is no convincing evidence that any particular medication is effective in treating the acute symptoms of sports concussion specifically. Treatment should be based on common approaches to each specific symptom (level of evidence C). Symptoms such as headache, sleep difficulty and depression may either be direct results of concussion or may represent exacerbations of pre-existing conditions.

In the acute setting, treatment options for headache are limited. Acetaminophen offers a possible benefit without significant increased bleeding risk. In general, aspirin (ASA) and nonsteroidal anti-inflammatories (NSAIDS) are not recommended as discussed previously. Physical modalities (ie, massage, ice, contrast therapy and manual therapy) may be considered, especially if there is concurrent neck pain. A dim, quiet environment may moderate head pain, as well as symptoms of photophobia and phonophobia. If headache continues even after 3-4 days, abortive treatment should be tailored to the headache type (ie, migraine, tension, occipital neuralgia, etc) (level of evidence C). Similarly, prophylactic treatment of a new or exacerbated chronic or recurrent headache syndrome should be tailored 
appropriately. Headaches that continue as part of a postconcussion syndrome (symptoms lasting longer than 6 weeks) often require a multidisciplinary approach. ${ }^{140}$

Sleep disturbance is a common and important symptom experienced throughout the course of a concussion. ${ }^{141}$ Immediately after a concussion, patients may experience either increased sleep latency, and frequent wakening, or decreased latency and longer sleep times. In either case, sleep issues in the first few days following injury onset should be addressed conservatively, without medications, and with particular attention to good sleep hygiene. Excessive daytime somnolence is also common, regardless of absolute sleep times. There is no evidence to support a role for stimulant or sleep-promoting medications in the acute setting. Sleep difficulties may continue as part of a postconcussion syndrome. In these cases, both medical and cognitive therapies may be considered.

Alteration in mood is also a common manifestation of concussion, particularly in the acute setting. ${ }^{142}$ While depression is perhaps the most common, any mood disturbance is possible. There is no established role for medications in the treatment of a concussion-induced mood disturbance. If mood issues persist beyond 6-12 weeks, either as part of a postconcussion syndrome, or as manifestations of an exacerbated mood disorder, treatment with medications and/or a cognitive therapy should be considered (level of evidence C).

Cognitive symptoms, especially decreased attention, may also produce significant morbidity. There is no established role for stimulant medications in the treatment of acute attention difficulties following a concussion (level of evidence C). Decreasing academic responsibilities and other cognitive demands should be considered for any significant decrease in cognitive performance. ${ }^{143}$

Symptoms of balance dysfunction and vertigo should be carefully evaluated prior to treatment. Medications such as meclizine or diazepam may be helpful for acute attacks of vertigo, but should be used cautiously early in concussion management as they may affect cognitive function, cause fatigue and obscure the evaluation of a concussion resolution. ${ }^{144}$ Although only limited evidence exists, a vestibular therapy may be considered for the treatment of dizziness or vertigo ${ }^{145}$ (level of evidence C).

\section{Return to school}

There are no standardised guidelines for returning the athlete to school. If the athlete develops increased symptoms with cognitive stress, student athletes may require academic accommodations such as a reduced workload, extended test-taking time, days off or a shortened school day. ${ }^{146}$ Some athletes have persistent neurocognitive deficits following a concussion, despite being symptom free. Consideration should be made to withhold an athlete from contact sports if they have not returned to their 'academic baseline' following their concussion ${ }^{126}$ (level of evidence C). The CDC developed educational materials for educators and school administrators that are available at no cost and can be obtained via the CDC website. Additional resources for academic accommodations should be developed for both clinicians and educators ${ }^{147}$ (level of evidence C).

\section{Return to play}

RTP after a concussion should be individualised, gradual and progressive and should consider factors that may affect individual risk and outcome 41529435895148 (level of evidence C). The athlete should be free of concussion symptoms at rest as well as during and after exertion before returning to full participation (level of evidence $\mathrm{C}$ ). The athlete should also have a normal neurological exam including a normal cognitive and
Table 4 Graduated return-to-play protocol

\begin{tabular}{ll}
\hline Rehabilitation stage & Objective of stage \\
\hline No activity & Recovery \\
Light aerobic exercise & Increase heart rate \\
Sport-specific exercise & Add movement \\
Non-contact training drills & $\begin{array}{l}\text { Exercise, coordination and cognitive load } \\
\text { Full-contact practise }\end{array}$ \\
$\begin{array}{ll}\text { Restore athlete's confidence; coaching staff } \\
\text { assesses functional skills }\end{array}$ \\
Return to play & \\
\hline
\end{tabular}

balance evaluation, ideally compared to a preinjury baseline (level of evidence C). Once the athlete is asymptomatic and has returned to their baseline measures (if available), a gradual and medically supervised incremental return to activity should be initiated and includes a stepwise increase in physical demands, sports-specific activities and physical contact. This progression may take days to weeks to months depending upon the individual responses and modifying circumstances. It is important to consider individual factors that are suspected to increase susceptibility and/or prolong recovery after a concussive injury. The severity of a concussion is based on the nature, burden and duration of symptoms, the frequency and past history of concussions, and the presence of prolonged symptoms. All should be considered while determining the symptom-free interval required prior to starting the RTP progression (level of evidence C).

The RTP progression should be individualised, with symptoms, cognitive and balance exams used for tracking recovery (level of evidence C). A typical RTP progression for an uncomplicated concussion is shown in table 4 . If the athlete develops symptoms with an increase in activity level, the progression should be stopped and the athlete returned to the previous phase when symptom-free again (level of evidence C). The RTP decision is individualised for the specific circumstances of each concussion. $^{15} 148$ A final RTP/practise determination should occur with documented medical clearance from a licenced healthcare provider trained in the evaluation and management of concussions (level of evidence $\mathrm{C}$ ).

\section{NEUROIMAGING}

The vast majority of athletes with a sports-related concussion do not require neuroimaging. ${ }^{149-154}$ Standard neuroimaging with a CT or MRI is negative in a concussion, but are used to evaluate for more serious brain injury. ${ }^{495} \mathrm{CT}$ is best used acutely for evaluating for bone fracture and for intracranial bleeding, contusion, mass effects and/or brain stem herniation, whereas an MRI is more sensitive for evaluating persistent or worsening symptoms or concern for underlying pathology (eg, headache or seizure disorder, arteriovenous malformation, Chiari malformation, etc). ${ }^{155} \mathrm{CT}$ exposes the brain to radiation and should be used judiciously. MRI technology has improved with stronger magnets and different techniques that can detect minor abnormalities after a concussion, although the clinical relevance of the findings is unclear.

Other imaging techniques used primarily in concussions research include positron emission tomography (PET) and single-photon emission CT (SPECT) imaging which measure cerebral glucose uptake and regional cerebral blood flow, respectively. Both PET and SPECT incorporate injected 
radioisotope, are time consuming and have undetermined predictive value which limits their clinical use.

A recent research is evaluating new neuroimaging techniques after sports-related concussions including functional MRI (fMRI), diffusion tensor imaging (DTI) and MR spectroscopy (MRS). fMRI demonstrates neuronal dysfunction by measuring regional changes in blood oxygenation patterns measured in response to a specific task that the individual performs while in the scanner. The information obtained is totally dependent on the tasks being performed (eg, working memory, sensorimotor coordination or visuospatial memory). Abnormal patterns of activation have been noted in several studies of sports-related concussions. ${ }^{155-163}$

DTI provides structural images of white matter fibre tracts of the brain by measuring the movement of water within the brain. Fractional anisotropy is a measure of the relative directionality of water diffusion in axons and in healthy individuals the direction is organised and in a specific direction (anisotropy). Both fractional anisotropy, and mean diffusivity have been shown to change after a sports-related concussion, though how these correlate with clinical measures of injury and recovery have not yet been elucidated. ${ }^{164-173}$

MRS measures neurometabolites via proton magnetic resonance spectroscopy (MRS) that are important in the neuropathology of a concussive injury. MRS typically evaluates $\mathrm{N}$-acetylaspartate, creatinine, choline, myoinositol and lactate and preliminary research in sports-related concussions show changes in the ratio of these neurometabolites in different areas of the brain. ${ }^{13} 173174$ The research involving the use of MRS as well as other advanced neuroimaging techniques is evolving rapidly, but currently there are no definitive clinical correlations to make them applicable to patient care.

\section{SHORT-TERM RISKS ASSOCIATED WITH PREMATURE RTP}

There are potential health risks of returning an athlete with persistent symptoms to play including the possibility of SIS or diffuse cerebral swelling, and increased susceptibility to a recurrent or more severe concussion and prolonged duration of symptoms. SIS is described as occurring when an individual sustains a second head injury before the symptoms associated with the initial injury have completely cleared. ${ }^{175}{ }^{176}$ The pathophysiology of SIS is thought to involve a loss of autoregulation of the brain's blood supply, leading to vascular engorgement, marked increase in intracranial pressure, brain herniation and ultimately coma or death. There is significant debate as to whether SIS is related to a prior head injury or if it represents a separate pathophysiological malignant brain oedema, a form of diffuse cerebral swelling described in children. ${ }^{177-179}$ The pathophysiology of diffuse cerebral swelling after the first impact is described in laboratory animal models. ${ }^{180} 181$ There are also limited cases of SIS reported in the literature and while rare, SIS is reported as more common in boxers and athletes under the age of 18 . The history and pathophysiology of death in some reported cases of SIS do not support the diagnosis. Whether or not a discrete entity of SIS exists, the association with concussion is a compelling reason why an athlete should not RTP before symptoms of his/her concussion have completely resolved.

Returning an athlete to play with persistent symptoms may predispose an athlete to a worse concussion (level of evidence B). A concussion decreases the cognitive ability and reaction time ${ }^{16} 51103125182$ which theoretically diminishes an athlete's ability to respond to the demands of the sport, increasing the risk of a second brain impact injury to other body parts. In addition, early activity after a concussion can prolong symptoms and neurocognitive recovery. ${ }^{183}$ On a pathophysiological basis; studies suggest there is an increased window of brain vulnerability after a concussion secondary to the impairment of cellular energy metabolism. ${ }^{9}$ A second injury before the brain has recovered results in worsening cellular metabolic changes and more significant cognitive deficits in animal laboratory models. 9 11-14 16184 In humans this may translate to increased susceptibility to a concussion, an increased morbidity from relatively lower forces or prolonged symptoms duration and a neurocognitive recovery.

\section{PROLONGED CONCUSSIVE SYMPTOMS/POSTCONCUSSION SYNDROME}

While the majority of concussions resolve within 7-10 days, in some cases symptoms persist for weeks, months or years beyond the initial injury. The evolution of a concussion injury to a postconcussion syndrome is ill-defined and poorly understood. It is difficult to define where concussion ends and postconcussion syndrome begins. The syndrome is simply defined as symptoms and signs of the concussion that persist for weeks to months after the incident. ${ }^{95}{ }^{185-187}$ Symptoms of a postconcussion syndrome can be subjective or objective and are often vague and non-specific making the diagnosis difficult. Although any symptom of concussion can be involved, commonly reported symptoms include headache, dizziness; insomnia; exercise intolerance; cognitive intolerance; psychological symptoms such as depressed mood, irritability and anxiety; cognitive problems involving memory loss, poor concentration and problem solving; fatigue; or noise and light sensitivity. ${ }^{81}$

While there are many potential causes of a postconcussion syndrome, none have been proven or accepted. There is, however, no proven correlation between the severity of the concussion injury and (1) the likelihood of developing persistent postconcussion symptoms, (2) any structural damage to the brain or disruption of neurotransmitter systems or (3) the presence of psychological factors like depression, anxiety or posttraumatic stress disorder. ${ }^{88}{ }^{143-145}$ Risk factors for a postconcussion syndrome include an increasing age, female sex (possibly because women are more likely to seek medical care when they have symptoms) or non-sports-related concussion (car collision, fall or assault). Compared to other forms of concussions, sportsrelated concussions seem less likely to result in a postconcussion syndrome. $^{88} 143-145$

The foundation of postconcussion syndrome management is time. Recovery from postconcussive syndrome can be a long and slow process that is often frustrating for patients and removes them from their normal endeavours in school and sports. Management of a postconcussion syndrome is ideally done by a team of providers who work with concussion on a regular basis (level of evidence C). Comprehensive NP evaluation by a trained neuropsychologist utilising standardised paper and pencil testing can be helpful in defining cognitive deficits and areas of potential neurocognitive rehabilitation (level of evidence C). Cognitive therapy, ${ }^{188}$ integrated neurorehabilitation programmes ${ }^{187}$ and supervised progressive exercise programmes may improve recovery ${ }^{189}$ (level of evidence B). Progressive exercise programmes involve exercising to the onset of symptoms, then every other day exercise at $80 \%$ of the symptom threshold, with retesting and progression of activity as tolerated. The general return-to-exercise recommendation is to advance slowly as symptoms permit. Similar to the management of concussion, athletes with a postconcussion syndrome will need academic and work-place accommodations to restrict or modify cognitive 
loads until learning processes have recovered. Treatment of coexistent or new mood and sleep disturbances may also be beneficial (level of evidence C).

\section{DISQUALIFICATION FROM SPORTS}

There are no evidence-based guidelines for disqualifying or retiring an athlete from their sport after concussion. Several authors have proposed that a clinician should consider disqualifying an athlete if any of the following are present: structural abnormality on neuroimaging; multiple lifetime concussions; persistent diminished academic or workplace performance; persistent postconcussive symptoms; prolonged recovery courses and perceived reduced threshold of sustaining recurrent concussions. ${ }^{190-195}$ There have been no agreed-upon absolute number of concussions an individual can sustain before disqualification from contact sports is necessary. Each case should be carefully deliberated with all parties involved with an understanding of risks and unknowns. An individualised approach to determining disqualification is essential (level of evidence C).

\section{LONG-TERM SEQUELAE OF SPORTS-RELATED CONCUSSIONS}

There is an increasing concern that head impact exposure and recurrent concussions contribute to long-term neurological sequelae including chronic traumatic encephalopathy (CTE) and chronic neurocognitive impairment (CNI). There is no known relationship between CNI and CTE.

CTE is a neurodegenerative disease associated with repetitive brain trauma and characterised pathologically by the accumulation of $\tau$ protein in specific areas of the brain. CTE results in executive dysfunction, memory impairment, depression and poor impulse control. ${ }^{196}$ CTE is a diagnosis made only after death with confirmatory histopathology, and the prevalence of this condition is unknown. Recent studies have described the histopathological findings of CTE in the postmortem analysis of athlete's brain tissue ${ }^{197-201}$ The typical symptoms and behaviours preceding death in athletes with CTE suggest a link between neurobehavioural patterns and the neuroanatomical areas of the brain affected. CTE is not a continuation of a postconcussion syndrome or symptoms from an acute concussion, but rather develops decades after exposure. Not all athletes diagnosed with a CTE postmortem reported concussions during play, raising the question if sub-concussive blows may contribute to the development of CTE. Given the large number of athletes participating in contact or collision sports and the small number of cases described, it is likely that other factors such as genetic predisposition play a role in its development. ${ }^{178} 196$

CNI after a head injury can present in postconcussive syndrome, but can also occur years after a symptom-free interval, and CNI symptoms and behaviours can be demonstrated by a NP testing. Some studies have identified an association between prior concussions and chronic cognitive dysfunction, ${ }^{37} 85202203$ but others have found no association. ${ }^{204-207}$ Studies involving former American football players ${ }^{42} 208$ and soccer players who were active at the time of the study ${ }^{209-211}$ suggest an increased risk of CNI with increased exposure to concussions and subconcussive insults to the head. Guskiewicz et al ${ }^{42} 208$ showed a higher incidence of mild cognitive impairment and depression in former NFL athletes with a history of a concussion compared to those who did not have a history of concussion. Matser showed decreased performance on NP testing in athletes who had a higher incidence of concussion and heading. 209-211 However, a community-based study of high-school football players in Minnesota with a long-term follow-up (median
50.2 years) showed no increase in dementia, Parkinson's disease or amyotrophic lateral sclerosis in football players compared to the general population. ${ }^{212}$ While the potential for CNI and CTE is concerning; large-scale, epidemiological studies are required to more clearly understand the causes and develop prevention strategies.

\section{EDUCATION}

Studies demonstrate that athletes, parents and coaches lack the knowledge needed to make informed decisions about concussions. ${ }^{213-215}$ Misconceptions and lack of understanding about symptoms of a concussion as well as the recommended treatment and RTP guidelines still exist. ${ }^{213} 215$ Administrators and coaches play a big part in the health and safety of the athlete and they are often the first source of knowledge for the athlete and parents on topics like concussions. ${ }^{213}$

Education of medical personnel, coaches, athletes and parents can enhance the identification of concussions and improve treatment and prevention (level of evidence C). Preseason education including symptoms and signs of concussion, proper fit and use of equipment, player respect, sport rules, sports-specific techniques, symptom reporting and assessment, treatment and testing options and RTP guidelines will help all to understand the significance and importance of this injury better. The education method and medium should be tailored to the group to optimise the learning method. ${ }^{216}$

Currently, there are a variety of concussion educational materials available through governmental, educational and private companies. Table 5 lists some recommended concussions education resources.

\section{PREVENTION OF SPORTS-RELATED CONCUSSIONS}

All sports-related concussion cannot be prevented, but several efforts may reduce the incidence and severity (level of evidence B). These changes will require a shift in attitude and expectation on the part of players, coaches, officials, administrators, parents and fans; especially with respect to contact and collision sports.

The rules of a play form the basis of a safe conduct for the game. Stringent enforcement of the rules by coaches and officials $^{217}$ and strict adherence to the rules by players might reduce the incidence of concussions. The rules of the game set expectations for behaviour on the field of play and define infractions for collisions with an increased risk to the aggrieved player. Rigorous education and consistent modelling of the rules by coaches and officials reinforce the importance of a clean play. Fair play rules were shown to reduce a concussion injury in hockey tournaments ${ }^{218}$ and may have similar benefits for other sports. Promoting a fair play encourages respect for opponents and emphasises safety precautions for athletes. Coaches, parents and managers must role model fair play values for effectiveness. Rule changes based on epidemiological data also have reduced a concussion and neck injury in some sports: (1) banning 'spear tackling' in American football, (2) enforcing no 'checking from behind' in ice hockey ${ }^{219}$ and (3) limiting 'elbow to head' contact in soccer. ${ }^{217}$

Table 5 Concussion education websites

\begin{tabular}{ll}
\hline NCAA Concussion programme & NCAA.org/concussion \\
CDC Concussion Education/Head Up & http://www.cdc.gov/concussion/sports \\
NFL Health and Safety & NFLhealthandsafety.com \\
\hline
\end{tabular}


Limiting the number of contact practises will reduce exposures and subsequently the number of concussions. This concept is being tested in American college football, college lacrosse and college soccer in some conferences, and if proven effective may also be beneficial in other sports such as ice hockey and rugby. ${ }^{220221}$ Similar restrictions in contact-collision for different age groups, such as prohibiting body checking in boys' lacrosse and ice hockey below the age of 13-15, also has the potential for preventing an injury.

Player behaviour plays an integral part in injury reduction. Athletes must be taught correct playing techniques and appropriate behaviour by trained and qualified coaches. Any behaviour that increases a concussion risk should be eliminated, and this may require a culture change in players, coaches, officials, administrators and fans. Sports-specific techniques like tackling, body checking and heading the ball must be properly taught and demonstrated before they are used in game situations.

Protective equipment has not yet shown a role in concussion reduction. $^{30} 222223$ Helmets have played a significant role in reducing scalp lacerations, skull fractures and intracranial bleeds, and their use in sports such as cycling, skiing and snowboarding should be strongly supported. While head gear and helmets can reduce biomechanical forces associated with a blow to the head and could possibly reduce concussion severity, helmet use has not been shown to prevent or reduce a concussion. ${ }^{222}$ There is a potential for improved helmet designs and for sports-specific helmets to decrease concussions in sports. Mouth guards prevent peri-oral and dental injuries, but there is little evidence that mouth guards reduce concussion rates. ${ }^{95} 131$ Often overlooked is the possibility that use of protective equipment may change player behaviour and secondarily contribute to an increase in a concussion risk.

Neck strengthening may limit transmitted forces to the head and dampen impact on the brain. Differences in head-necksegment mass and girth have been demonstrated between women and men, and may underlie the differences seen in reported concussions incidences between genders. ${ }^{60} 224$ From a theoretical standpoint, increasing the strength and rigidity of the head-neck segment could decrease the acceleration forces seen by the head when struck. However, neck-strengthening programmes have not yet, to date, been published that demonstrate a significant intervention effect. In addition, the benefits of stronger neck muscles are not effective when the athlete has no opportunity to 'prepare' for impact as often occurs in rule infractions.

Educating athletes, parents, coaches, administrators, athletic trainers and physicians involved in contact and collision sports is important for athlete safety (level of evidence C). An understanding of the risks, detection and assessment techniques and the principles of safe RTP should help improve concussion safety.

\section{LEGISLATION}

Concussion-related legislation in many states requires education of athletes, parents or guardians and coaches, removal from play or practise at the time of a suspected concussion and written clearance for RTP or practise by a licenced healthcare provider trained in the evaluation and management of concussions. Such laws provide a uniform standard for scholastic and nonscholastic sports organisations regarding concussion safety and management. ${ }^{225}$ These efforts have arisen as safety measures to improve the care of this injury by standardising the roles and responsibilities of athletes, parents or guardians, coaches and healthcare providers. ${ }^{225}$ Healthcare providers should be aware of the laws in the state where they practise. Over 4 of 5 states have laws in place, and there are ongoing efforts to establish legislation in all 50 states. $^{226}$ These laws should be viewed living documents to be modified as the best educational policies and practises are developed, the most effective strategies for implementing and measuring compliance of the laws are determined, and as new knowledge about sports concussions develops. ${ }^{225}$

\section{CONCLUSIONS}

Concussion is a concerning and complicated problem in sports requiring a multifaceted approach to diagnosis and management. Athletes, coaches, officials and parents need to be educated regarding signs and symptoms of concussions to recognise the injury on the field of play and to seek appropriate evaluation. It is critical that athletes are forthcoming regarding their symptoms as this is often the only detectable indication of concussions. A physician or other health professional trained in the evaluation and management of concussion who knows the athlete well is in the best position to correctly diagnose a concussed athlete. Standardised sideline tests provide a helpful, uniform approach for examination but further studies are needed to delineate their accuracy. No athlete diagnosed with a concussion should RTP on the same day or while symptomatic. The RTP decision is a medical one. Additional research is needed to validate current assessment tools, further delineate the role of NP and balance testing, validate RTP guidelines and improve identification of those at risk for prolonged concussive symptoms or other short-term or long-term complications.

Acknowledgements Endorsed by the National Trainers' Athletic Association and the American College of Sports Medicine.

Funding None.

Competing interests None.

Provenance and peer review Commissioned; internally peer reviewed.

\section{REFERENCES}

1 Aubry M, Cantu R, Dvorak J, et al. Summary and agreement statement of the First International Conference on Concussion in Sport, Vienna 2001. Recommendations for the improvement of safety and health of athletes who may suffer concussive injuries. Br J Sports Med 2002;36:6-10.

2 McCrory $P$, Johnston $K$, Meeuwisse $W$, et al. Summary and agreement statement of the 2nd International Conference on Concussion in Sport, Prague 2004. Br J Sports Med 2005;39:196-204.

3 Guskiewicz KM, Bruce SL, Cantu RC, et al. National athletic trainers' association position statement: management of sport-related concussion. J Athletic Training 2004;39:280-97.

4 Herring SA, Cantu RC, Guskiewicz KM, et al. Concussion (mild traumatic brain injury) and the team physician: a consensus statement-2011 update. Med Sci Sports Exerc 2011;43:2412-22.

5 McCrory P, Meeuwisse W, Johnston K, et al. Consensus statement on concussion in sport: the 3rd International Conference on Concussion in Sport held in Zurich, November 2008. Br J Sports Med 2009:43(Suppl 1):i76-90.

6 Meehan WP III, d'Hemecourt P, Comstock RD. High school concussions in the 2008-2009 academic year: mechanism, symptoms, and management. Am J Sports Med 2010;38:2405-9.

7 Ebell MH, Siwek J, Weiss BD, et al. Strength of recommendation taxonomy (sort): a patient-centered approach to grading evidence in the medical literature. Am Fam Phys 2004;69:548-56.

8 Prins $M L$, Hales $A$, Reger $M$, et al. Repeat traumatic brain injury in the juvenile rat is associated with increased axonal injury and cognitive impairments. Dev Neurosci 2010;32:510-18.

9 Shrey DW, Griesbach GS, Giza CC. The pathophysiology of concussions in youth. Phys Med Rehabil Clin N Am 2011;22:577-602, vii.

10 Barkhoudarian G, Hovda DA, Giza CC. The molecular pathophysiology of concussive brain injury. Clin Sports Med 2011;30:33-48, vii-iii.

11 Vagnozzi R, Tavazzi B, Signoretti S, et al. Temporal window of metabolic brain vulnerability to concussions: mitochondrial-related impairment-part i. Neurosurgery 2007;61:379-88; discussion.

12 Vagnozzi R, Signoretti S, Cristofori $L$, et al. Assessment of metabolic brain damage and recovery following mild traumatic brain injury: a multicentre, proton magnetic resonance spectroscopic study in concussed patients. Brain 2010;133:3232-42. 
13 Vagnozzi R, Signoretti S, Tavazzi B, et al. Temporal window of metabolic brain vulnerability to concussion: A pilot $1 \mathrm{~h}$-magnetic resonance spectroscopic study in concussed athletes—part iii. Neurosurgery 2008;62:1286-95; discussion.

14 Tavazzi B, Vagnozzi R, Signoretti S, et al. Temporal window of metabolic brain vulnerability to concussions: oxidative and nitrosative stresses-part ii. Neurosurgery 2007;61:390-5, discussion 395-396.

15 Esposito G, Van Horn JD, Weinberger DR, et al. Gender differences in cerebral blood flow as a function of cognitive state with pet. J Nucl Med 1996;37:559-64.

16 Longhi $\mathrm{L}$, Saatman $\mathrm{KE}$, Fujimoto $\mathrm{S}$, et al. Temporal window of vulnerability to repetitive experimental concussive brain injury. Neurosurgery 2005;56:364-74; discussion.

17 Lincoln AE, Hinton RY, Almquist JL, et al. Head, face, and eye injuries in scholastic and collegiate lacrosse: a 4-year prospective study. Am J Sports Med 2007:35:207-15.

18 Hootman JM, Dick R, Agel J. Epidemiology of collegiate injuries for 15 sports: summary and recommendations for injury prevention initiatives. J Athletic Training 2007:42:311-19.

19 Langlois JA, Rutland-Brown W, Wald MM. The epidemiology and impact of traumatic brain injury: a brief overview. J Head Trauma Rehabil 2006;21:375-8

20 Gessel LM, Fields SK, Collins CL, et al. Concussions among United States high school and collegiate athletes. J Athletic Training 2007;42:495-503.

21 Powell JW, Barber-Foss KD. Traumatic brain injury in high school athletes. JAMA 1999;282:958-63.

22 Bakhos LL, Lockhart GR, Myers R, et al. Emergency department visits for concussion in young child athletes. Pediatrics 2010;126:e550-6.

23 Lincoln AE, Caswell SV, Almquist JL, et al. Trends in concussion incidence in high school sports: a prospective 11-year study. Am J Sports Med 2011;39:958-63.

24 Schulz MR, Marshall SW, Mueller FO, et al. Incidence and risk factors for concussion in high school athletes, North Carolina, 1996-1999. Am J Epidemiol 2004; 160:937-44

25 Marar M, Mcllvain NM, Fields SK, et al. Epidemiology of concussions among United States high school athletes in 20 sports. Am J Sports Med 2012:40:747-55.

26 McCrea M, Hammeke T, Olsen G, et al. Unreported concussion in high school football players: implications for prevention. Clin J Sport Med 2004;14:13-17.

27 Valovich McLeod TC, Bay RC, Heil J, et al. Identification of sport and recreational activity concussion history through the preparticipation screening and a symptom survey in young athletes. Clin J Sport Med 2008;18:235-40.

28 Williamson IJ, Goodman D. Converging evidence for the under-reporting of concussions in youth ice hockey. Br J Sports Med 2006;40:128-32; discussion.

29 Makdissi M, Darby D, Maruff $\mathrm{P}$, et al. Natural history of concussion in sport: markers of severity and implications for management. Am J Sports Med 2010;38:464-71.

30 Benson BW, Hamilton GM, Meeuwisse WH, et al. Is protective equipment useful in preventing concussion? A systematic review of the literature. Br J Sports Med 2009;43(Suppl 1):i56-67.

31 Collins MW, Iverson GL, Lovell MR, et al. On-field predictors of neuropsychological and symptom deficit following sports-related concussion. Clin J Sport Med 2003;13:222-9.

32 McCrea M, Barr WB, Guskiewicz K, et al. Standard regression-based methods for measuring recovery after sport-related concussion. J Int Neuropsychol Soc 2005; 11:58-69.

33 McCrory P. Refshauge lecture. When to retire after concussion? I Sci Med Sport 2002;5:169-82.

34 Mansell JL, Tierney RT, Higgins $\mathrm{M}$, et al. Concussive signs and symptoms following head impacts in collegiate athletes. Brain Inj 2010;24:1070-4.

35 Jinguji TM, Bompadre V, Harmon KG, et al. Sport concussion assessment tool-2: baseline values for high school athletes. Br J Sports Med 2012;46:365-70.

36 McLeod TC, Leach C. Psychometric properties of self-report concussion scales and checklists. J Athletic Training 2012;47:221-3.

37 Preiss-Farzanegan SJ, Chapman B, Wong TM, et al. The relationship between gender and postconcussion symptoms after sport-related mild traumatic brain injury. Pm R 2009;1:245-53.

38 Colvin AC, Mullen J, Lovell MR, et al. The role of concussion history and gender in recovery from soccer-related concussion. Am J Sports Med 2009;37:1699-704.

39 Frommer LJ, Gurka KK, Cross KM, et al. Sex differences in concussion symptoms of high school athletes. J Athletic Training 2011;46:76-84.

40 Lovell M, Collins M, Bradley J. Return to play following sports-related concussion. Clin Sports Med 2004;23:421-41, ix.

41 Emery C, Kang J, Shrier I, et al. Risk of injury associated with bodychecking experience among youth hockey players. CMAJ 2011;183:1249-56.

42 Guskiewicz KM, Marshall SW, Bailes J, et al. Recurrent concussion and risk of depression in retired professional football players. Med Sci Sports Exerc 2007;39:903-9.

43 Guskiewicz KM, McCrea M, Marshall SW, et al. Cumulative effects associated with recurrent concussion in collegiate football players: the ncaa concussion study. JAMA 2003:290:2549-55.
44 Guskiewicz KM, Weaver NL, Padua DA, et al. Jr. Epidemiology of concussion in collegiate and high school football players. Am J Sports Med 2000;28: 643-50.

45 Hollis SJ, Stevenson MR, McIntosh AS, et al. Incidence, risk, and protective factors of mild traumatic brain injury in a cohort of Australian nonprofessional male rugby players. Am J Sports Med 2009;37:2328-33.

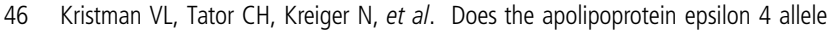
predispose varsity athletes to concussion? A prospective cohort study. Clin I Sport Med 2008;18:322-8.

47 Bruce JM, Echemendia RJ. Concussion history predicts self-reported symptoms before and following a concussive event. Neurology 2004;63:1516-18.

48 Iverson GL, Gaetz M, Lovell MR, et al. Cumulative effects of concussion in amateur athletes. Brain Inj 2004;18:433-43.

49 Schatz P, Moser RS, Covassin T, et al. Early indicators of enduring symptoms in high school athletes with multiple previous concussions. Neurosurgery 2011;68:1562-7; discussion 1567

50 Lau B, Lovell MR, Collins MW, et al. Neurocognitive and symptom predictors of recovery in high school athletes. Clin J Sport Med 2009;19:216-21.

51 Slobounov S, Slobounov E, Sebastianelli W, et al. Differential rate of recovery in athletes after first and second concussion episodes. Neurosurgery 2007:61:338-44; discussion 344.

52 Iverson GL, Gaetz M, Lovell MR, et al. Relation between subjective fogginess and neuropsychological testing following concussion. J Int Neuropsychol Soc 2004;10:904-6.

53 Iverson $\mathrm{G}$. Predicting slow recovery from sport-related concussion: the new simple-complex distinction. Clin J Sport Med 2007;17:31-7.

54 Lau BC, Kontos AP, Collins MW, et al. Which on-field signs/symptoms predict protracted recovery from sport-related concussion among high school football players? Am J Sports Med 2011;39:2311-18.

55 Covassin T, Swanik CB, Sachs ML. Sex differences and the incidence of concussions among collegiate athletes. J Athletic Training 2003;38:238-44.

56 Dick RW. Is there a gender difference in concussion incidence and outcomes? $\mathrm{Br} J$ Sports Med 2009;43(Suppl 1):i46-50.

57 Broshek DK, Kaushik T, Freeman JR, et al. Sex differences in outcome following sports-related concussion. J Neurosurg 2005;102:856-63.

58 Kutcher JS, Eckner JT. At-risk populations in sports-related concussion. Curr Sports Med Rep 2010;9:16-20.

59 Covassin T, Swanik CB, Sachs M, et al. Sex differences in baseline neuropsychological function and concussion symptoms of collegiate athletes. $\mathrm{Br} \mathrm{J}$ Sports Med 2006;40:923-7; discussion 927

60 Tierney RT, Sitler MR, Swanik CB, et al. Gender differences in head-neck segment dynamic stabilization during head acceleration. Med Sci Sports Exerc 2005;37:272-9.

61 Gioia GA, Collins M, Isquith PK. Improving identification and diagnosis of mild traumatic brain injury with evidence: psychometric support for the acute concussion evaluation. J Head Trauma Rehabil 2008;23:230-42.

62 Daneshvar DH, Nowinski CJ, McKee AC, et al. The epidemiology of sport-related concussion. Clin Sports Med 2011;30:1-17, vii.

63 Guskiewicz KM, Valovich McLeod TC. Pediatric sports-related concussion. Pm R 2011;3:353-64; quiz 364.

64 Giza CC, Hovda DA. The neurometabolic cascade of concussion. J Athletic Training 2001:36:228-35.

65 Zuckerman SL, Odom M, Lee YM, et al. 145 sport-related concussion and age: number of days to neurocognitive baseline. Neurosurgery 2012;71:E558.

66 Field M, Collins MW, Lovell MR, et al. Does age play a role in recovery from sports-related concussion? A comparison of high school and collegiate athletes. J Pediatr 2003;142:546-53.

67 Moser RS, Schatz P, Jordan BD. Prolonged effects of concussion in high school athletes. Neurosurgery 2005;57:300-6; discussion.

68 Sim A, Terryberry-Spohr L, Wilson KR. Prolonged recovery of memory functioning after mild traumatic brain injury in adolescent athletes. J Neurosurg 2008; 108:511-16

69 Bruce DA, Schut L, Sutton LN. Brain and cervical spine injuries occurring during organized sports activities in children and adolescents. Prim Care 1984:11:175-94.

70 Kirkwood MW, Yeates KO, Wilson PE. Pediatric sport-related concussion: a review of the clinical management of an oft-neglected population. Pediatrics 2006;117:1359-71.

71 Snoek JW, Minderhoud JM, Wilmink JT. Delayed deterioration following mild head injury in children. Brain 1984;107(Pt 1):15-36.

72 Pellman EJ, Powell JW, Viano DC, et al. Concussion in professional football: epidemiological features of game injuries and review of the literature-part 3 Neurosurgery 2004;54:81-94; discussion 86-94

73 Yard EE, Schroeder MJ, Fields SK, et al. The epidemiology of United States high school soccer injuries, 2005-2007. Am J Sports Med 2008;36:1930-7.

74 Dick R, Putukian M, Agel J, et al. Descriptive epidemiology of collegiate women's soccer injuries: National collegiate athletic association injury surveillance system, 1988-1989 through 2002-2003. J Athletic Training 2007;42:278-85. 
75 Agel J, Evans TA, Dick R, et al. Descriptive epidemiology of collegiate men's soccer injuries: National collegiate athletic association injury surveillance system, 1988-1989 through 2002-2003. J Athletic Training 2007;42:270-7.

76 Boden BP, Kirkendall DT, Garrett WE Jr. Concussion incidence in elite college soccer players. Am J Sports Med 1998:26:238-41.

77 Terrell TR, Bostick RM, Abramson R, et al. Apoe, apoe promoter, and tau genotypes and risk for concussion in college athletes. Clin J Sport Med 2008;18:10-17.

78 Tierney RT, Mansell JL, Higgins M, et al. Apolipoprotein e genotype and concussion in college athletes. Clin J Sport Med 2010;20:464-8.

79 Terrell TR, Bostick RM, Barth JT, et al. Prospective cohort study of the association of genetic polymorphisms and concussion risk and postconcussion neurocognitive deficits in college athletes. (abstract). Clin J Sport Med 2012;22:172.

80 Schaal K, Tafflet M, Nassif $\mathrm{H}$, et al. Psychological balance in high level athletes: gender-based differences and sport-specific patterns. PLoS One 2011;6:e19007.

81 Kontos AP, Covassin T, Elbin RJ, et al. Depression and neurocognitive performance after concussion among male and female high school and collegiate athletes. Arch Phys Med Rehab 2012;93:1751-6.

82 Erlanger DM, Kutner KC, Barth JT, et al. Neuropsychology of sports-related head injury: dementia pugilistica to post concussion syndrome. Clin Neuropsychol 1999;13:193-209.

83 Bailey CM, Samples HL, Broshek DK, et al. The relationship between psychological distress and baseline sports-related concussion testing. Clin J Sport Med 2010;20:272-7.

84 Covassin T, Elbin RJ III, Larson E, et al. Sex and age differences in depression and baseline sport-related concussion neurocognitive performance and symptoms. Clin J Sport Med 2012;22:98-104.

85 Collins MW, Grindel SH, Lovell MR, et al. Relationship between concussion and neuropsychological performance in college football players. JAMA 1999:282:964-70.

86 Lau BC, Collins MW, Lovell MR. Sensitivity and specificity of subacute computerized neurocognitive testing and symptom evaluation in predicting outcomes after sports-related concussion. Am J Sports Med 2011;39:1209-16.

87 Lau BC, Collins MW, Lovell MR. Cutoff scores in neurocognitive testing and symptom clusters that predict protracted recovery from concussions in high school athletes. Neurosurgery 2012;70:371-9; discussion 379.

88 Solomon GS, Haase RF. Biopsychosocial characteristics and neurocognitive test performance in national football league players: an initial assessment. Arch Clin Neuropsychol 2008;23:563-77.

89 Kinart CM, Cuppett MM, Berg K. Prevalence of migraines in ncaa division I male and female basketball players. National Collegiate Athletic Association. Headache 2002;42:620-9

90 Lipton RB, Pan J. Is migraine a progressive brain disease? JAMA 2004;291:493-4.

91 Robbins MS, Lipton RB. The epidemiology of primary headache disorders. Semin Neurol 2010;30:107-19.

92 Gordon KE, Dooley JM, Wood EP. Is migraine a risk factor for the development of concussion? Br J Sports Med 2006:40:184-5.

93 Mihalik JP, Stump JE, Collins MW, et al. Posttraumatic migraine characteristics in athletes following sports-related concussion. J Neurosurg 2005;102:850-5.

94 Bernhardt D, Roberts W. Preparticipation physical evaluation monograph. 2010.

95 McCrory P. Sport concussion assessment tool 2. Scand J Med Sci Sports 2009;19:452.

96 Collie A, Darby D, Maruff P. Computerised cognitive assessment of athletes with sports related head injury. Br J Sports Med 2001;35:297-302.

97 Echemendia RJ, Bruce JM, Bailey CM, et al. The utility of post-concussion neuropsychological data in identifying cognitive change following sports-related mtbi in the absence of baseline data. Clin Neuropsychol 2012;26:1077-91.

98 Hunt TN, Ferrara MS. Age-related differences in neuropsychological testing among high school athletes. J Athletic Training 2009;44:405-9.

99 Greenwald BD, Cifu DX, Marwitz JH, et al. Factors associated with balance deficits on admission to rehabilitation after traumatic brain injury: a multicenter analysis. J Head Trauma Rehabil 2001;16:238-52

100 Rinne MB, Pasanen ME, Vartiainen MV, et al. Motor performance in physically well-recovered men with traumatic brain injury. J Rehabil Med 2006;38:224-9.

101 Kaufman KR, Brey RH, Chou LS, et al. Comparison of subjective and objective measurements of balance disorders following traumatic brain injury. Med Eng Phys 2006:28:234-9.

102 Geurts AC, Ribbers GM, Knoop JA, et al. Identification of static and dynamic postural instability following traumatic brain injury. Arch Phys Med Rehabil 1996;77:639-44.

103 McCrea M, Guskiewicz KM, Marshall SW, et al. Acute effects and recovery time following concussion in collegiate football players: the ncaa concussion study. JAMA 2003;290:2556-63.

104 Riemann BL, Guskiewicz K, Shields EW. Relationship between clinical and forceplate measures of postural stability. J Sport Rehabil 1999;8:71-82.

105 Peterson CL, Ferrara MS, Mrazik M, et al. Evaluation of neuropsychological domain scores and postural stability following cerebral concussion in sports. Clin J Sport Med 2003:13:230-7.
106 Guskiewicz K, Ross SE, Marshall SW. Postural stability and neuropsychological deficits after concussion in collegiate athletes. J Athletic Training 2001;36:263-73.

107 Riemann BL, Guskiewicz KM. Effects of mild head injury on postural stability as measured through clinical balance testing. J Athletic Training 2000;35:19-25.

108 Finnoff JT, Peterson VJ, Hollman JH, et al. Intrarater and interrater reliability of the balance error scoring system (BESS). Pm R 2009;1:50-4.

109 Mulligan I, Boland M, Payette J. Prevalence of neurocognitive and balance deficits in collegiate aged football players without clinically diagnosed concussion. J Orthop Sports Phys Ther 2012;42:625-32.

110 Broglio SP, Puetz TW. The effect of sport concussion on neurocognitive function, self-report symptoms and postural control: a meta-analysis. Sports Med 2008;38:53-67.

111 Register-Mihalik JK, Mihalik JP, Guskiewicz KM. Balance deficits after sports-related concussion in individuals reporting posttraumatic headache. Neurosurgery 2008;63:76-80; discussion 72-80.

112 Koehler DM, Shipman J, Davidson MA, et al. Is early venous thromboembolism prophylaxis safe in trauma patients with intracranial hemorrhage. J Trauma 2011;70:324-9.

113 Depew AJ, Hu CK, Nguyen AC, et al. Thromboembolic prophylaxis in blunt traumatic intracranial hemorrhage: a retrospective review. Am Surg 2008:74:906-11.

114 Norwood SH, Berne JD, Rowe SA, et al. Early venous thromboembolism prophylaxis with enoxaparin in patients with blunt traumatic brain injury. J Trauma 2008;65:1021-6; discussion 1026-1027.

115 Echemendia RJ, Herring S, Bailes J. Who should conduct and interpret the neuropsychological assessment in sports-related concussion? Br J Sports Med 2009;43(Suppl 1):i32-5.

116 Johnson EW, Kegel NE, Collins MW. Neuropsychological assessment of sport-related concussion. Clin Sports Med 2011;30:73-88, viii-ix.

117 Ellemberg D, Henry LC, Macciocchi SN, et al. Advances in sport concussion assessment: from behavioral to brain imaging measures. J Neurotrauma 2009;26:2365-82.

118 Fazio VC, Lovell MR, Pardini JE, et al. The relation between post concussion symptoms and neurocognitive performance in concussed athletes. NeuroRehabilitation 2007;22:207-16.

119 Van Kampen DA, Lovell MR, Pardini JE, et al. The 'value added' of neurocognitive testing after sports-related concussion. Am J Sports Med 2006;34:1630-5.

120 Iverson GL, Lovell MR, Collins MW. Interpreting change on impact following sport concussion. Clin Neuropsychol 2003;17:460-7.

121 Randolph C, McCrea M, Barr WB. Is neuropsychological testing useful in the management of sport-related concussion? J Athletic Training 2005;40:139-52.

$122 \mathrm{McC}$ rory P. Sports concussion and the risk of chronic neurological impairment. Clin J Sport Med 2011;21:6-12.

123 Randolph C, Lovell M, Laker SR. Neuropsychological testing point/counterpoint. Pm R 2011;3:S433-9.

124 Collie A, Maruff $P$, Makdissi M, et al. Statistical procedures for determining the extent of cognitive change following concussion. Br J Sports Med 2004;38:273-8

125 Sullivan SJ, Bourne L, Choie S, et al. Understanding of sport concussion by the parents of young rugby players: a pilot study. Clin J Sport Med 2009;19:228-30.

126 Broglio SP, Macciocchi SN, Ferrara MS. Sensitivity of the concussion assessment battery. Neurosurgery 2007;60:1050-7; discussion 1057-1058.

127 McCrory PR, Berkovic SF. Video analysis of acute motor and convulsive manifestations in sport-related concussion. Neurology 2000;54:1488-91.

128 McCrory P. Using a sledgehammer to crack a walnut: the modern management of concussion. Inj Prev 2007;13:364-5.

129 Schmidt JD, Register-Mihalik JK, Mihalik JP, et al. Identifying impairments after concussion: normative data versus individualized baselines. Med Sci Sports Exerc 2012:44:1621-8.

130 McCrory P. Future advances and areas of future focus in the treatment of sport-related concussion. Clin Sports Med 2011;30:201-8, xi-ii.

131 McCrory P. Do mouthguards prevent concussion? Br J Sports Med 2001;35:81-2

132 Register-Mihalik JK, Guskiewicz KM, Mihalik JP, et al. Reliable change, sensitivity, and specificity of a multidimensional concussion assessment battery: implications for caution in clinical practice. J Head Trauma Rehabil. Published Online First: 9 June 2012. doi 10.1097/HTR.0b013e3182585d37.

133 Schatz P. Long-term test-retest reliability of baseline cognitive assessments using impact. Am J Sports Med 2010:38:47-53.

134 Erdal K. Neuropsychological testing for sports-related concussion: how athletes can sandbag their baseline testing without detection. Arch Clin Neuropsychol 2012:27:473-9.

135 Register-Mihalik JK, Kontos DL, Guskiewicz KM, et al. Age-related differences and reliability on computerized and paper-and-pencil neurocognitive assessment batteries. J Athletic Training 2012;47:297-305.

136 Schatz P, Moser RS, Solomon GS, et al. Prevalence of invalid computerized baseline neurocognitive test results in high school and collegiate athletes. J Athletic Training 2012:47:289-96. 
137 Covassin T, Elbin RJ, Harris W, et al. The role of age and sex in symptoms, neurocognitive performance, and postural stability in athletes after concussion. Am J Sports Med 2012;40:1303-12.

138 Hutchison M, Comper P, Mainwaring L, et al. The influence of musculoskeletal injury on cognition: implications for concussion research. Am J Sports Med 2011;39:2331-7

139 Jones N, Young C, Walter K. Effect of education and language on baseline concussion screening tests in professional baseball players. CJSM 2011;21:153-84.

140 Seifert TD, Evans RW. Posttraumatic headache: a review. Curr Pain Headache Rep 2010;14:292-8

141 Schreiber S, Barkai G, Gur-Hartman T, et al. Long-lasting sleep patterns of adult patients with minor traumatic brain injury (MTBI) and non-MTBI subjects. Sleep Med 2008:9:481-7.

142 Busch CR, Alpern HP. Depression after mild traumatic brain injury: a review of current research. Neuropsychol Rev 1998:8:95-108.

143 Reddy CC, Collins M, Lovell M, et al. Efficacy of amantadine treatment on symptoms and neurocognitive performance among adolescents following sports-related concussion. J Head Trauma Rehabil. Published Online First: 18 May 2012. doi:10.1097/HTR.0b013e318257fbc6.

144 Strupp M, Thurtell MJ, Shaikh AG, et al. Pharmacotherapy of vestibular and ocular motor disorders, including nystagmus. J Neurol 2011;258:1207-22.

145 Alsalaheen BA, Mucha A, Morris LO, et al. Vestibular rehabilitation for dizziness and balance disorders after concussion. J Neurol Phys Ther 2010;34:87-93.

146 McGrath N. Supporting the student-athlete's return to the classroom after a sport-related concussion. J Athletic Training 2010;45:492-8.

147 Schneiders AG, Sullivan SJ, Handcock P, et al. Sports concussion assessment: the effect of exercise on dynamic and static balance. Scand J Med Sci Sports 2012;22:85-90.

148 Putukian M, Aubry M, McCrory P. Return to play after sports concussion in elite and non-elite athletes? Br J Sports Med 2009;43(Suppl 1):i28-31.

149 Davis GA, Iverson GL, Guskiewicz KM, et al. Contributions of neuroimaging, balance testing, electrophysiology and blood markers to the assessment of sport-related concussion. Br J Sports Med 2009;43(Suppl 1):i36-45.

150 Smits M, Houston GC, Dippel DW, et al. Microstructural brain injury in post-concussion syndrome after minor head injury. Neuroradiology 2011;53:553-63

151 Pulsipher DT, Campbell RA, Thoma R, et al. A critical review of neuroimaging applications in sports concussion. Curr Sports Med Rep 2011;10:14-20.

152 Prabhu SP. The role of neuroimaging in sport-related concussion. Clin Sports Med 2011:30:103-14, ix.

153 Echemendia RJ, Putukian M, Mackin RS, et al. Neuropsychological test performance prior to and following sports-related mild traumatic brain injury. Clin J Sport Med 2001;11:23-31

154 Amen DG, Trujillo $M$, Newberg $A$, et al. Brain spect imaging in complex psychiatric cases: an evidence-based, underutilized tool. Open Neuroimag J 2011;5:40-8.

155 Kelly $A B$, Zimmerman RD, Snow RB, et al. Head trauma: comparison of MR and CT-experience in 100 patients. AJNR Am J Neuroradiol 1988;9:699-708.

156 Slobounov SM, Zhang K, Pennell D, et al. Functional abnormalities in normally appearing athletes following mild traumatic brain injury: a functional MRI study. Exp Brain Res 2010;202:341-54

157 Talavage TM, Nauman E, Breedlove EL, et al. Functionally-detected cognitive impairment in high school football players without clinically-diagnosed concussion. J Neurotrauma. Published Online First: 1 October 2010. doi:10.1089/ neu.2010.1512.

158 Ptito A, Chen JK, Johnston KM. Contributions of functional magnetic resonance imaging (fmri) to sport concussion evaluation. NeuroRehabilitation 2007:22:217-27.

159 Gosselin N, Bottari C, Chen JK, et al. Electrophysiology and functional mri in post-acute mild traumatic brain injury. J Neurotrauma 2011;28:329-41.

160 Keightley ML, Chiew KS, Winocur G, et al. Age-related differences in brain activity underlying identification of emotional expressions in faces. Soc Cogn Affect Neurosci 2007;2:292-302.

161 Jantzen $\mathrm{KJ}$, Oullier $\mathrm{O}$, Marshall $\mathrm{M}$, et al. A parametric fmri investigation of context effects in sensorimotor timing and coordination. Neuropsychologia 2007:45:673-84

162 Chen JK, Johnston KM, Petrides M, et al. Neural substrates of symptoms of depression following concussion in male athletes with persisting postconcussion symptoms. Arch Gen Psychiatry 2008;65:81-9.

163 Chen JK, Johnston KM, Frey S, et al. Functional abnormalities in symptomatic concussed athletes: an fmri study. Neuroimage 2004;22:68-82.

164 Zhang $K$, Johnson B, Pennell D, et al. Are functional deficits in concussed individuals consistent with white matter structural alterations: combined fmri \& dti study. Exp Brain Res 2010;204:57-70.

165 Schaefer PW, Huisman TA, Sorensen AG, et al. Diffusion-weighted MR imaging in closed head injury: high correlation with initial glasgow coma scale score and score on modified rank in scale at discharge. Radiology 2004;233:58-66.
166 Oni MB, Wilde EA, Bigler ED, et al. Diffusion tensor imaging analysis of frontal lobes in pediatric traumatic brain injury. J Child Neurol 2010;25:976-84.

167 Wozniak JR, Krach L, Ward E, et al. Neurocognitive and neuroimaging correlates of pediatric traumatic brain injury: a diffusion tensor imaging (dti) study. Arch Clin Neuropsychol 2007;22:555-68.

168 Niogi SN, Mukherjee P, Ghajar J, et al. Extent of microstructural white matter injury in postconcussive syndrome correlates with impaired cognitive reaction time: a $3 t$ diffusion tensor imaging study of mild traumatic brain injury. AJNR Am J Neuroradiol 2008;29:967-73.

169 Levin HS, Wilde E, Troyanskaya M, et al. Diffusion tensor imaging of mild to moderate blast-related traumatic brain injury and its sequelae. J Neurotrauma 2010;27:683-94.

170 Kraus MF, Susmaras T, Caughlin BP, et al. White matter integrity and cognition in chronic traumatic brain injury: a diffusion tensor imaging study. Brain 2007;130:2508-19.

171 Cubon VA, Putukian M, Boyer $C$, et al. A diffusion tensor imaging study on the white matter skeleton in individuals with sports-related concussion. J Neurotrauma 2011;28:189-201.

172 Huisman TA. Diffusion-weighted imaging: basic concepts and application in cerebral stroke and head trauma. Eur Radiol 2003;13:2283-97.

173 Henry LC, Tremblay S, Boulanger Y, et al. Neurometabolic changes in the acute phase after sports concussions correlate with symptom severity. J Neurotrauma 2010;27:65-76.

174 Yeo RA, Gasparovic C, Merideth F, et al. A longitudinal proton magnetic resonance spectroscopy study of mild traumatic brain injury. J Neurotrauma 2011:28:1-11.

175 Cantu RC. Second-impact syndrome. Clin Sports Med 1998;17:37-44.

176 Cantu RC, Gean AD. Second-impact syndrome and a small subdural hematoma: an uncommon catastrophic result of repetitive head injury with a characteristic imaging appearance. J Neurotrauma 2010;27:1557-64.

177 McCrory P. Does second impact syndrome exist? Clin J Sport Med 2001;11:144-9

178 McCrory P, Davis G, Makdissi M. Second impact syndrome or cerebral swelling after sporting head injury. Curr Sports Med Rep 2012;11:21-3.

179 Kors EE, Terwindt GM, Vermeulen FL, et al. Delayed cerebral edema and fatal coma after minor head trauma: role of the cacna1a calcium channel subunit gene and relationship with familial hemiplegic migraine. Ann Neurol 2001;49:753-60.

180 Atkinson JL, Anderson RE, Murray MJ. The early critical phase of severe head injury: importance of apnea and dysfunctional respiration. J Trauma 1998:45:941-5

181 Engelborghs K, Verlooy J, Van Reempts J, et al. Temporal changes in intracranial pressure in a modified experimental model of closed head injury. J Neurosurg 1998;89:796-806.

182 Lovell MR, Collins MW. Neuropsychological assessment of the college football player. J Head Trauma Rehabil 1998;13:9-26.

183 Majerske CW, Mihalik JP, Ren D, et al. Concussion in sports: postconcussive activity levels, symptoms, and neurocognitive performance. J Athletic Training 2008;43:265-74.

184 Kissick J, Johnston KM. Return to play after concussion: principles and practice. Clin J Sport Med 2005;15:426-31.

185 Ryan LM, Warden DL. Post concussion syndrome. Int Rev Psychiatry 2003;15:310-16.

186 Jotwani V, Harmon KG. Postconcussion syndrome in athletes. Curr Sports Med Rep 2010;9:21-6.

187 McAllister TW, Arciniegas D. Evaluation and treatment of postconcussive symptoms. NeuroRehabilitation 2002;17:265-83.

188 Iverson GL. Outcome from mild traumatic brain injury. Curr Opin Psychiatry 2005; 18:301-17.

189 Leddy JJ, Kozlowski K, Donnelly JP, et al. A preliminary study of subsymptom threshold exercise training for refractory post-concussion syndrome. Clin J Sport Med 2010;20:21-7.

190 Sedney $\mathrm{CL}$, Orphanos J, Bailes JE. When to consider retiring an athlete after sports-related concussion. Clin Sports Med 2011;30:189-200, xi.

191 De Beaumont L, Mongeon D, Tremblay S, et al. Persistent motor system abnormalities in formerly concussed athletes. J Athletic Training 2011;46:234-40.

192 De Beaumont L, Tremblay S, Poirier J, et al. Altered bidirectional plasticity and reduced implicit motor learning in concussed athletes. Cereb Cortex 2012:22:112-21.

193 De Beaumont L, Theoret $\mathrm{H}$, Mongeon D, et al. Brain function decline in healthy retired athletes who sustained their last sports concussion in early adulthood. Brain 2009;132:695-708

194 Cantu RC. Recurrent athletic head injury: risks and when to retire. Clin Sports Med 2003;22:593-603, $x$

195 McCrory P. What advice should we give to athletes postconcussion? Br J Sports Med 2002:36:316-18.

196 Baugh CM, Stamm JM, Riley DO, et al. Chronic traumatic encephalopathy: neurodegeneration following repetitive concussive and subconcussive brain trauma. Brain Imaging Behav 2012;6:244-54

197 McKee AC, Cantu RC, Nowinski CJ, et al. Chronic traumatic encephalopathy in athletes: progressive tauopathy after repetitive head injury. J Neuropathol Exp Neurol 2009:68:709-35. 
198 Omalu BI, Bailes J, Hammers JL, et al. Chronic traumatic encephalopathy, suicides and parasuicides in professional American athletes: the role of the forensic pathologist. Am J Forensic Med Pathol 2010;31:130-2.

199 Omalu BI, DeKosky ST, Minster RL, et al. Chronic traumatic encephalopathy in a national football league player. Neurosurgery 2005;57:128-34; discussion 128134.

200 Omalu BI, Fitzsimmons RP, Hammers J, et al. Chronic traumatic encephalopathy in a professional American wrestler. J Forensic Nurs 2010;6:130-6.

201 Omalu BI, Hamilton RL, Kamboh MI, et al. Chronic traumatic encephalopathy (CTE) in a national football league player: case report and emerging medicolegal practice questions. J Forensic Nurs 2010;6:40-6.

202 Shuttleworth-Edwards AB, Smith I, Radloff SE. Neurocognitive vulnerability amongst university rugby players versus noncontact sport controls. J Clin Exp Neuropsychol 2008;30:870-84

203 Thornton AE, Cox DN, Whitfield K, et al. Cumulative concussion exposure in rugby players: neurocognitive and symptomatic outcomes. J Clin Exp Neuropsychol 2008;30:398-409.

204 Bruce JM, Echemendia RJ. History of multiple self-reported concussions is not associated with reduced cognitive abilities. Neurosurgery 2009;64:100-6; discussion 106.

205 Collie A, McCrory P, Makdissi M. Does history of concussion affect current cognitive status? Br J Sports Med 2006;40:550-1.

206 Rutherford A, Stephens R, Fernie G, et al. Do UK university football club players suffer neuropsychological impairment as a consequence of their football (soccer) play? J Clin Exp Neuropsychol 2009;31:664-81.

207 McAllister TW, Flashman LA, Maerlender A, et al. Cognitive effects of one season of head impacts in a cohort of collegiate contact sport athletes. Neurology 2012;78:1777-84

208 Guskiewicz KM, Marshall SW, Bailes J, et al. Association between recurrent concussion and late-life cognitive impairment in retired professional football players. Neurosurgery 2005;57:719-26.

209 Matser JT, Kessels AG, Lezak MD, et al. A dose-response relation of headers and concussions with cognitive impairment in professional soccer players. J Clin Exp Neuropsychol 2001;23:770-4.

210 Matser JT, Kessels AG, Jordan BD, et al. Chronic traumatic brain injury in professional soccer players. Neurology 1998:51:791-6.
211 Matser EJ, Kessels AG, Lezak MD, et al. Neuropsychological impairment in amateur soccer players. JAMA 1999;282:971-3.

212 Savica R, Parisi JE, Wold LE, et al. High school football and risk of neurodegeneration: A community-based study. Mayo Clin Proc 2012;87:335-40.

213 Sye G, Sullivan SJ, McCrory P. High school rugby players' understanding of concussion and return to play guidelines. Br J Sports Med 2006;40:1003-5.

214 Kaut KP, DePompei R, Kerr J, et al. Reports of head injury and symptom knowledge among college athletes: implications for assessment and educational intervention. Clin J Sport Med 2003;13:213-21.

215 Valovich McLeod TC, Schwartz C, Bay RC. Sport-related concussion misunderstandings among youth coaches. Clin J Sport Med 2007;17:140-2.

216 Provvidenza CF, Johnston KM. Knowledge transfer principles as applied to sport concussion education. Br J Sports Med 2009;43(Suppl 1):i68-75.

217 Anderson SD. Bodychecking in hockey. CMAJ 2004;170:16; author reply 16, 18.

218 Roberts WO, Brust JD, Leonard B, et al. Fair-play rules and injury reduction in ice hockey. Arch Pediatr Adolesc Med 1996;150:140-5.

219 Grindel SH, Lovell MR, Collins MW. The assessment of sport-related concussion: the evidence behind neuropsychological testing and management. Clin J Sport Med 2001;11:134-43.

220 Ivy league presidents approve concussion recommendations for lacrosse and men's and women's soccer. Press Release. July 16, 2012

221 Ivy league presidents approve concussion curbing measures for football. Press Release. July 20, 2011

222 Daneshvar DH, Baugh CM, Nowinski CJ, et al. Helmets and mouth guards: the role of personal equipment in preventing sport-related concussions. Clin Sports Med 2011;30:145-63, x.

223 Navarro RR. Protective equipment and the prevention of concussion-what is the evidence? Curr Sports Med Rep 2011;10:27-31.

224 Tierney RT, Higgins M, Caswell SV, et al. Sex differences in head acceleration during heading while wearing soccer headgear. J Athletic Training 2008;43:578-84

225 Adler $\mathrm{RH}$, Herring SA. Changing the culture of concussion: Education meets legislation. Pm R 2011;3:S468-70.

226 The Zackery Lystedt law. http://www.nflevolution.com/article/ The-Zackery-Lystedt-Law?ref=270 (accessed 14 Oct 2012). 


\section{Correction}

Harmon KG, Drezner JA, Gammons M, et al. American Medical Society for Sports Medicine position statement: concussion in sport. Br J Sports Med 2013;47:15-26. "National Athletic Trainers' Association" appears incorrectly in the article as "National Trainers' Athletic Association".

Br J Sports Med 2013;47:184. doi:10.1136/bjsports-2012-091941corr1 